\title{
Parametric sensitivity and uncertainty analysis of dimethylsulfide oxidation in the clear-sky remote marine boundary layer
}

\author{
D. D. Lucas ${ }^{1, *}$ and R. G. Prinn ${ }^{1}$ \\ ${ }^{1}$ Department of Earth, Atmospheric, and Planetary Sciences, MIT, Cambridge, MA 02139, USA \\ * present address: Frontier Research Center for Global Change, Japan Agency for Marine-Earth Science and Technology, \\ Yokohama, Japan
}

Received: 18 August 2004 - Published in Atmos. Chem. Phys. Discuss.: 7 October 2004

Revised: 2 May 2005 - Accepted: 18 May 2005 - Published: 17 June 2005

\begin{abstract}
Local and global sensitivity and uncertainty methods are applied to a box model of the dimethylsulfide (DMS) oxidation cycle in the remote marine boundary layer in order to determine the key physical and chemical parameters and sources of uncertainty. The model considers 58 uncertain parameters, and simulates the diurnal gas-phase cycles of DMS, $\mathrm{SO}_{2}$, methanesulfonic acid (MSA), and $\mathrm{H}_{2} \mathrm{SO}_{4}$ for clear-sky summertime conditions observed over the Southern Ocean. The results of this study depend on many underlying assumptions, including the DMS mechanism, simulation conditions, and probability distribution functions of the uncertain parameters. A local direct integration method is used to calculate first-order local sensitivity coefficients for infinitesimal perturbations about the parameter means. Key parameters identified by this analysis are related to DMS emissions, vertical mixing, heterogeneous removal, and the $\mathrm{DMS}+\mathrm{OH}$ abstraction and addition reactions. MSA and $\mathrm{H}_{2} \mathrm{SO}_{4}$ are also sensitive to numerous rate constants, which limits the ability of using parameterized mechanisms to predict their concentrations. Of the chemistry, $\mathrm{H}_{2} \mathrm{SO}_{4}$ is highly sensitive to the rate constants for a set of nighttime reactions that lead to its production through a non- $\mathrm{SO}_{2}$ path initiated by the oxidation of DMS by $\mathrm{NO}_{3}$. For the global analysis, the probabilistic collocation method is used to propagate the uncertain parameters through the model. The concentrations of DMS and $\mathrm{SO}_{2}$ are uncertain $(1-\sigma)$ by factors of 3.5 and 2.5 , respectively, while MSA and $\mathrm{H}_{2} \mathrm{SO}_{4}$ have uncertainty factors that range between 4.1 and 8.6. The main sources of uncertainty in the four species are from DMS emissions and heterogeneous scavenging, but the uncertain rate constants collectively account for up to 59\% of the total uncertainty in MSA and 43\% in $\mathrm{H}_{2} \mathrm{SO}_{4}$. Of the uncertain DMS chemistry, reactions that form and destroy $\mathrm{CH}_{3} \mathrm{~S}(\mathrm{O}) \mathrm{OO}$ and $\mathrm{CH}_{3} \mathrm{SO}_{3}$ are identified as important targets for reducing the uncertainties.
\end{abstract}

Correspondence to: D. D. Lucas

(ddlucas@alum.mit.edu)

\section{Introduction}

The production of dimethylsulfide $\left(\mathrm{CH}_{3} \mathrm{SCH}_{3}\right.$, DMS $)$ by marine phytoplankton (Keller et al., 1989) is believed to be the largest source of natural sulfur to the global atmosphere (Bates et al., 1992). In the atmosphere DMS is photochemically oxidized to a multitude of sulfur-bearing species, many of which have an affinity for interacting with existing, or creating new, aerosols. These connections form part of a proposed feedback whereby DMS may influence climate and radiation on a planetary scale (Shaw, 1983; Charlson et al., 1987). Although the proposed DMS-climate link has sparked extensive research (Restelli and Angeletti, 1993; Andreae and Crutzen, 1997), many large sources of uncertainty still remain. Two widely used sea-air transfer velocities, for instance, yield DMS fluxes that differ by a factor of two (Liss and Merlivat, 1986; Wanninkhof, 1992). As another example, the formation rates of new sulfate aerosols differ by an order of magnitude between two recent studies (Kulmala et al., 1998; Verheggen and Mozurkewich, 2002).

Another recognized, but not well quantified, source of uncertainty arises from the gas-phase oxidation of DMS. The oxidation steps involve many species, competing reactions, and multiple branch points (Yin et al., 1990; Turnipseed and Ravishankara, 1993; Urbanski and Wine, 1999; Lucas and Prinn, 2002). Only a small number of the DMS-related rate constants have been measured in the laboratory, so the majority are estimated (i.e. they are highly uncertain). Quantifying the effects of these uncertain chemical reactions on predictions of the sulfur-containing species is therefore vital. Moreover, it is critical to rank the uncertain DMS chemistry relative to uncertain non-photochemical processes (e.g. DMS emissions and heterogeneous scavenging). By applying parametric sensitivity and uncertainty techniques, a quantitative comparison of these uncertainties is reported here, with the goal of stimulating further research into the relevant areas.

(C) 2005 Author(s). This work is licensed under a Creative Commons License. 


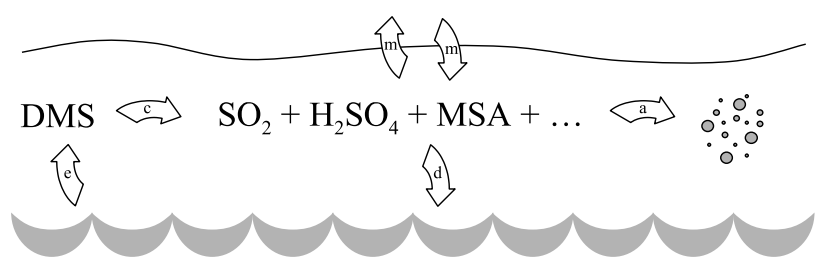

Fig. 1. Major processes affecting gas-phase DMS-related species in the clear-sky RMBL: $e=$ emissions of DMS from the ocean, $c=$ chemical oxidation, $d=$ dry deposition, $a=$ loss to background aerosols, and $m=$ mixing in to and out of the RMBL.

Few sensitivity and uncertainty studies have been performed on systems containing comprehensive DMS oxidation chemistry. In one recent study, Capaldo and Pandis (1997) calculated the sensitivities of the DMS-related concentrations to chemical and physical parameters for different mechanisms in a box model of the remote marine boundary layer (RMBL). Their model predictions were particularly sensitive to the parameters associated with DMS emissions, heterogeneous processes, and vertical mixing. Their investigation, however, emphasized structural uncertainties, not parametric uncertainties. That is, they analyzed the differences arising from different structural representations of DMS chemistry (i.e. different DMS mechanisms), but not the uncertainties caused by the uncertain chemical parameters. They did not consider specifically the sensitivities to rate constants and the propagation of rate constant uncertainties to the species concentrations. Furthermore, as noted by Saltelli (1999), Capaldo and Pandis (1997) applied a sensitivity technique that was unable to capture parameter interactions affecting the sulfur-bearing compounds.

Saltelli and Hjorth (1995) also analyzed the sensitivities and uncertainties of DMS oxidation chemistry, but instead focused on a parametric analysis. They computed the sensitivities and uncertainties of ratios of important sulfurcontaining end products to the kinetic parameters in a moderately complex DMS mechanism. Extensions of their work appeared subsequently in Campolongo et al. (1999) and Saltelli (1999). Using Monte Carlo and regression methods, Saltelli and Hjorth (1995) explicitly accounted for system non-linearities by sampling the uncertainty spaces of the rate constants. Contingent upon their model structure, they identified and ranked the most important kinetic parameters. Their model, however, lacked crucial non-photochemical processes (e.g. DMS emissions and heterogeneous scavenging), so they could not rank the relative importance of uncertainties in DMS chemistry versus physical processes. Moreover, their model did not include diurnal variations that are known to play a large role in the DMS cycle in the RMBL (i.e. constant $\mathrm{OH}$ levels were used).

In this report, we attempt to bridge the gaps in these previous studies by performing a parametric sensitivity and uncertainty analysis on a model of the DMS cycle in the RMBL.
As described in Sect. 2, this model includes comprehensive, diurnally-varying sulfur chemistry and important physical source and removal processes. Our primary goals are to identify the influential parameters in the system (sensitivity analysis) and quantify the net amounts and sources of uncertainty (uncertainty analysis) in our sulfur concentration predictions. Because our model is time-dependent and has many highly uncertain parameters, we apply two methods to analyze the sensitivities and uncertainties. These methods are described in Sect. 3. The first method is a standard local technique known as the direct integration method that is convenient for computing first-order local sensitivities as a function of time (Dickinson and Gelinas, 1976; Leis and Kramer, 1988a). The second method is a recent global technique known as the probabilistic collocation method (Tatang et al., 1997) that quantifies uncertainties and uncertainty contributions in complex nonlinear models.

Given the detailed focus of our sensitivity and uncertainty analysis, we restrict our attention to a DMS mechanism at a single set of atmospheric conditions. These conditions correspond to summertime RMBL observations collected aboard a flight over the Southern Ocean. Our specific results, therefore, hinge on these conditions and our choice of DMS mechanism. A parametric analysis of another DMS mechanism under semi-polluted conditions, for example, would likely identify an alternate set of important DMS-based parameters. Nonetheless, our study highlights certain parameters that require additional scrutiny in the laboratory or field in order to reduce the uncertainties of observable sulfur-bearing species in the RMBL.

There are many sulfur-containing species that participate in the DMS cycle, but we report here on the sensitivities and uncertainties of the four primary observable gas-phase DMS-related species. These species are DMS, sulfur dioxide $\left(\mathrm{SO}_{2}\right)$, sulfuric acid $\left(\mathrm{H}_{2} \mathrm{SO}_{4}\right)$ and methanesulfonic acid $\left(\mathrm{CH}_{3} \mathrm{SO}_{3} \mathrm{H}, \mathrm{MSA}\right)$. We note that DMS is widely observed because it is the major source of sulfur in the marine atmosphere, while $\mathrm{SO}_{2}, \mathrm{MSA}$, and $\mathrm{H}_{2} \mathrm{SO}_{4}$ are often observed because they are critical in forming or modifying aerosols.

\section{DMS chemistry in the clear-sky RMBL}

\subsection{Model description and processes}

The gaseous sulfur-based species in the clear-sky RMBL are affected by many processes. The reduced sulfur compounds (e.g. DMS) are susceptible to chemical oxidation, while the oxidized sulfur compounds (e.g. MSA and $\mathrm{H}_{2} \mathrm{SO}_{4}$ ) are soluble and easily scavenged by wet aerosols. Some of the species (e.g. DMS and $\mathrm{SO}_{2}$ ) also have long enough lifetimes for transport processes to influence their budgets. Assuming the RMBL is horizontally homogeneous, the transport mechanism involves vertical exchange between the boundary layer 
and overlying free troposphere. Figure 1 illustrates these processes.

The effects of these processes on the sulfur-containing species are described by coupled ordinary differential equations (ODEs) of the form

$$
\frac{d n_{i}}{d t}=f_{i}\left(n, p_{c}\right)-p_{h, i} n_{i}+p_{m}\left(n_{f, i}-n_{i}\right)+p_{e, i},
$$

where $n_{i}$ and $n_{f, i}$ are the gas-phase number concentrations of sulfur-based species $i$ in the RMBL and free troposphere, respectively, $f$ is the net chemical production function, and the $p$ 's are the process parameters. Specifically, $p_{c}$ represents the set of gas-phase chemical reaction rate constants, $p_{h}$ is the first-order heterogeneous removal parameter, $p_{m}$ is associated with the parameterized mixing, and $p_{e}$ is the oceanic emissions source. As shown in Table 1, our DMS model includes 25 sulfur-based species and 58 uncertain parameters (49 gas phase and 9 non-gas phase). The coupled ODEs for these 25 species are solved simultaneously using a stiff ODE solver (i.e. no steady-state approximations are assumed).

As given by Eq. (1), our DMS model is structurally simple because it has only four general types of processes (emissions, chemistry, heterogeneous removal, and vertical mixing). Though structurally simple, we have confidence that our model adequately describes the essential processes occuring in the DMS cycle in the clear-sky RMBL for two reasons. First, this model reproduces the general features of the boundary layer observations of DMS, $\mathrm{SO}_{2}, \mathrm{MSA}$, and $\mathrm{H}_{2} \mathrm{SO}_{4}$ analyzed in Lucas and Prinn (2002). Second, similar box models have been used to examine field observations of DMS-related species in the tropical Pacific and Southern Oceans (Davis et al., 1999; Chen et al., 2000; Shon et al., 2001).

The major limitations in Eq. (1) are the lack of cloud processes and aqueous-phase chemistry. This restricts our study to clear-sky conditions, but still leaves a rich set of uncertainties associated with gas-phase DMS oxidation chemistry and additional non-gas-phase processes. The set of uncertainties pertaining to aqueous-phase chemistry and cloud microphysics will require attention in future studies. Another limitation in Eq. (1) involves the use of simple parameters, instead of complex dynamical representations, for the physical processes. We assign reasonable values for these parameters, however, as described in Sects. 2.1.2 to 2.1.4. We recognize the shortcomings of this approach, so we also assign large uncertainties to these physical parameters.

\subsubsection{Gas-phase DMS chemistry}

The gas-phase oxidation of DMS is calculated using a mechanism containing 49 sulfur-containing reactions. In addition to DMS, $\mathrm{SO}_{2}, \mathrm{MSA}$, and $\mathrm{H}_{2} \mathrm{SO}_{4}$, this mechanism includes dimethylsulfoxide $\left(\mathrm{CH}_{3} \mathrm{~S}(\mathrm{O}) \mathrm{CH}_{3}, \mathrm{DMSO}\right)$, dimethylsulfone
$\left(\mathrm{CH}_{3} \mathrm{~S}(\mathrm{O})_{2} \mathrm{CH}_{3}, \mathrm{DMSO}_{2}\right)$, methanesulfenic acid $\left(\mathrm{CH}_{3} \mathrm{SOH}\right.$, MSEA), and methanesulfinic acid $\left(\mathrm{CH}_{3} \mathrm{~S}(\mathrm{O}) \mathrm{OH}\right.$, MSIA). Except for the changes noted later in this section, the reactions and rate constants are from the DMS mechanism in Lucas and Prinn (2002). The rate constants from that study have been set for the conditions of this current study (see Table 2). This DMS mechanism is ultimately derived from the Yin et al. (1990) scheme, but minimized for RMBL conditions (e.g. low $\mathrm{NO}_{\mathrm{x}}$ concentrations and no sulfur-sulfur reactions). As detailed in Lucas and Prinn (2002), the original Yin et al. (1990) rate constants were updated primarily using the recommended values in DeMore et al. (1997), though values were also taken from Atkinson et al. (1997) and other direct sources. Additional descriptions of this specific DMS mechanism are in Lucas (2003) and Lucas and Prinn (2003), while broader reviews of DMS chemistry in general are found in Turnipseed and Ravishankara (1993), Berresheim et al. (1995), and Urbanski and Wine (1999).

Briefly, the DMS oxidation scheme is initialized by reactions with $\mathrm{OH}$ and $\mathrm{NO}_{3}$, where the former occurs through two independent branches and the latter is potentially important at night (e.g. Allan et al., 1999). Initialization by halogens may also be important (e.g. von Glasow et al., 2002; von Glasow and Crutzen, 2004), but is neglected here due to poorly-constrained reactive halogen concentrations in the RMBL. Oxidation by $\mathrm{OH}$ tends to dominate the net photochemical loss of DMS in the RMBL because of the relatively abundant $\mathrm{OH}$ levels and large $\mathrm{OH}$-related rate constants. To calculate the nighttime oxidation of DMS by $\mathrm{NO}_{3}$, we include the $\mathrm{DMS}+\mathrm{NO}_{3}$ reaction using the rate constant from DeMore et al. (1997). After the initial oxidation of DMS by $\mathrm{OH}$ and $\mathrm{NO}_{3}$, the main oxidants in the mechanism are $\mathrm{HO}_{\mathrm{x}}$ and $\mathrm{O}_{3}$ because $\mathrm{NO}_{\mathrm{x}}$ levels are relatively low in the RMBL. Rather than predicting these oxidants directly in our model, we use measurement-based values to enable a specific focus on the sulfur-based chemistry.

As previously mentioned, DMS is oxidized by $\mathrm{OH}$ through two independent branches. These are the H-abstraction and $\mathrm{OH}$-addition channels shown below:

$$
\begin{aligned}
\mathrm{CH}_{3} \mathrm{SCH}_{3}+\mathrm{OH} \stackrel{\text { abs }}{\longrightarrow} \mathrm{CH}_{3} \mathrm{~S}(\mathrm{OH}) \mathrm{CH}_{3} \mathrm{SCH}_{2}+\mathrm{H}_{2} \mathrm{O} .
\end{aligned}
$$

The $\mathrm{H}$-abstraction branch is favored at higher temperatures and leads to the $\mathrm{CH}_{3} \mathrm{SO}_{\mathrm{x}}$ radicals ( $x=0$ to 3 ), which subsequently react to form $\mathrm{MSA}, \mathrm{SO}_{2}$ and $\mathrm{H}_{2} \mathrm{SO}_{4}$ through the general sequence:

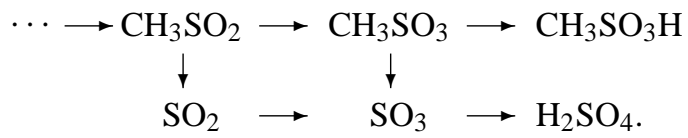

The key branching points in the above sequence involve the $\mathrm{CH}_{3} \mathrm{SO}_{\mathrm{x}}$ reactions leading to $\mathrm{MSA}$ versus the $\mathrm{CH}_{3} \mathrm{SO}_{\mathrm{x}}$ dissociations leading to $\mathrm{SO}_{2}$ and $\mathrm{H}_{2} \mathrm{SO}_{4}$. The above sequence 
Table 1. Processes and parameters in the box model of DMS chemistry in the RMBL. The mean values $(\bar{p})$ and uncertainty factors $(\phi)$ of the parameters are listed for the specific conditions of this study (see Table 2). For parameter values at other conditions refer to Lucas and Prinn (2002). The parameter units are: first-order chemistry, $\mathrm{s}^{-1}$; second-order chemistry, $\mathrm{cm}^{3}$ molecule $\mathrm{s}^{-1} \mathrm{~s}^{-1}$ heterogeneous loss, $\mathrm{s}^{-1}$; DMS surface emission, molecules $\mathrm{cm}^{-3} \mathrm{~s}^{-1}$; and RMBL mixing coefficient, $\mathrm{s}^{-1}$.

\begin{tabular}{|c|c|c|c|}
\hline \multicolumn{2}{|c|}{ Process } & $\bar{p}$ & $\phi$ \\
\hline \multicolumn{4}{|c|}{ Gas-Phase DMS Chemistry } \\
\hline 1 & $\mathrm{CH}_{3} \mathrm{SCH}_{3}+\mathrm{OH} \rightarrow \mathrm{CH}_{3} \mathrm{SCH}_{2}+\mathrm{H}_{2} \mathrm{O}$ & $4.85 \mathrm{E}-12$ & 1.2 \\
\hline 2 & $\mathrm{CH}_{3} \mathrm{SCH}_{3}+\mathrm{NO}_{3} \rightarrow \mathrm{CH}_{3} \mathrm{SCH}_{2}+\mathrm{HNO}_{3}$ & $1.1 \mathrm{E}-12$ & 1.2 \\
\hline 3 & $\mathrm{CH}_{3} \mathrm{SCH}_{3}+\mathrm{OH} \rightarrow \mathrm{CH}_{3} \mathrm{~S}(\mathrm{OH}) \mathrm{CH}_{3}$ & $3.1 \mathrm{E}-12$ & 2.0 \\
\hline 4 & $\mathrm{CH}_{3} \mathrm{~S}(\mathrm{OH}) \mathrm{CH}_{3} \rightarrow \mathrm{CH}_{3} \mathrm{SCH}_{3}+\mathrm{OH}$ & $2.2 \mathrm{E} 6$ & 2.0 \\
\hline 5 & $\mathrm{CH}_{3} \mathrm{~S}(\mathrm{OH}) \mathrm{CH}_{3}+\mathrm{O}_{2} \rightarrow \mathrm{CH}_{3} \mathrm{~S}(\mathrm{O}) \mathrm{CH}_{3}+\mathrm{HO}_{2}$ & $5.0 \mathrm{E}-13$ & 1.5 \\
\hline 6 & $\mathrm{CH}_{3} \mathrm{~S}(\mathrm{OH}) \mathrm{CH}_{3} \rightarrow \mathrm{CH}_{3} \mathrm{SOH}+\mathrm{CH}_{3}$ & $5.0 \mathrm{E} 5$ & 3.5 \\
\hline 7 & $\mathrm{CH}_{3} \mathrm{~S}(\mathrm{O}) \mathrm{CH}_{3}+\mathrm{OH} \rightarrow \mathrm{CH}_{3} \mathrm{~S}(\mathrm{O})(\mathrm{OH}) \mathrm{CH}_{3}$ & $1.0 \mathrm{E}-10$ & 1.3 \\
\hline 8 & $\mathrm{CH}_{3} \mathrm{~S}(\mathrm{O})(\mathrm{OH}) \mathrm{CH}_{3}+\mathrm{O}_{2} \rightarrow \mathrm{CH}_{3} \mathrm{~S}(\mathrm{O})_{2} \mathrm{CH}_{3}+\mathrm{HO}_{2}$ & $1.0 \mathrm{E}-13$ & 3.5 \\
\hline 9 & $\mathrm{CH}_{3} \mathrm{~S}(\mathrm{O})(\mathrm{OH}) \mathrm{CH}_{3} \rightarrow \mathrm{CH}_{3} \mathrm{~S}(\mathrm{O}) \mathrm{OH}+\mathrm{CH}_{3}$ & $2.0 \mathrm{E} 6$ & 3.5 \\
\hline 10 & $\mathrm{CH}_{3} \mathrm{~S}(\mathrm{O}) \mathrm{OH}+\mathrm{OH} \rightarrow \mathrm{CH}_{3} \mathrm{SO}_{2}+\mathrm{H}_{2} \mathrm{O}$ & $9.0 \mathrm{E}-11$ & 3.5 \\
\hline 11 & $\mathrm{CH}_{3} \mathrm{SCH}_{2}+\mathrm{O}_{2} \rightarrow \mathrm{CH}_{3} \mathrm{SCH}_{2} \mathrm{OO}$ & $5.7 \mathrm{E}-12$ & 1.1 \\
\hline 12 & $\mathrm{CH}_{3} \mathrm{SCH}_{2} \mathrm{OO}+\mathrm{NO} \rightarrow \mathrm{CH}_{3} \mathrm{SCH}_{2} \mathrm{O}+\mathrm{NO}_{2}$ & $1.2 \mathrm{E}-11$ & 3.5 \\
\hline 13 & $\mathrm{CH}_{3} \mathrm{SCH}_{2} \mathrm{O} \rightarrow \mathrm{CH}_{3} \mathrm{~S}+\mathrm{CH}_{2} \mathrm{O}$ & $3.3 \mathrm{E} 4$ & 3.5 \\
\hline 14 & $\mathrm{CH}_{3} \mathrm{SOH}+\mathrm{OH} \rightarrow \mathrm{CH}_{3} \mathrm{SO}+\mathrm{H}_{2} \mathrm{O}$ & $5.0 \mathrm{E}-11$ & 3.5 \\
\hline 15 & $\mathrm{CH}_{3} \mathrm{SOH}+\mathrm{HO}_{2} \rightarrow \mathrm{CH}_{3} \mathrm{SO}+\mathrm{H}_{2} \mathrm{O}_{2}$ & $8.5 \mathrm{E}-13$ & 3.5 \\
\hline 16 & $\mathrm{CH}_{3} \mathrm{SOH}+\mathrm{CH}_{3} \mathrm{O}_{2} \rightarrow \mathrm{CH}_{3} \mathrm{SO}+\mathrm{CH}_{3} \mathrm{O}_{2} \mathrm{H}$ & $8.5 \mathrm{E}-13$ & 3.5 \\
\hline 17 & $\mathrm{CH}_{3} \mathrm{~S}+\mathrm{NO}_{2} \rightarrow \mathrm{CH}_{3} \mathrm{SO}+\mathrm{NO}$ & $6.4 \mathrm{E}-11$ & 1.2 \\
\hline 18 & $\mathrm{CH}_{3} \mathrm{~S}+\mathrm{O}_{3} \rightarrow \mathrm{CH}_{3} \mathrm{SO}+\mathrm{O}_{2}$ & $5.5 \mathrm{E}-12$ & 1.2 \\
\hline 19 & $\mathrm{CH}_{3} \mathrm{~S}+\mathrm{O}_{2} \rightarrow \mathrm{CH}_{3} \mathrm{SOO}$ & $3.1 \mathrm{E}-14$ & 2.0 \\
\hline 20 & $\mathrm{CH}_{3} \mathrm{SOO} \rightarrow \mathrm{CH}_{3} \mathrm{~S}+\mathrm{O}_{2}$ & $1.8 \mathrm{E} 5$ & 2.0 \\
\hline 21 & $\mathrm{CH}_{3} \mathrm{SOO}+\mathrm{NO} \rightarrow \mathrm{CH}_{3} \mathrm{SO}+\mathrm{NO}_{2}$ & $1.1 \mathrm{E}-11$ & 2.0 \\
\hline 22 & $\mathrm{CH}_{3} \mathrm{SOO}+\mathrm{NO}_{2} \rightarrow \mathrm{CH}_{3} \mathrm{SOONO}_{2}$ & $2.2 \mathrm{E}-11$ & 2.0 \\
\hline 23 & $\mathrm{CH}_{3} \mathrm{SOONO}_{2} \rightarrow \mathrm{CH}_{3} \mathrm{SOO}+\mathrm{NO}_{2}$ & $4.0 \mathrm{E}-3$ & 3.5 \\
\hline 24 & $\mathrm{CH}_{3} \mathrm{SO}+\mathrm{NO}_{2} \rightarrow \mathrm{CH}_{3} \mathrm{SO}_{2}+\mathrm{NO}$ & $1.2 \mathrm{E}-11$ & 1.5 \\
\hline 25 & $\mathrm{CH}_{3} \mathrm{SO}+\mathrm{O}_{3} \rightarrow \mathrm{CH}_{3} \mathrm{SO}_{2}+\mathrm{O}_{2}$ & $6.0 \mathrm{E}-13$ & 1.5 \\
\hline 26 & $\mathrm{CH}_{3} \mathrm{SO}+\mathrm{O}_{2} \rightarrow \mathrm{CH}_{3} \mathrm{~S}(\mathrm{O}) \mathrm{OO}$ & $8.1 \mathrm{E}-14$ & 3.5 \\
\hline 27 & $\mathrm{CH}_{3} \mathrm{~S}(\mathrm{O}) \mathrm{OO} \rightarrow \mathrm{CH}_{3} \mathrm{SO}+\mathrm{O}_{2}$ & $4.7 \mathrm{E} 5$ & 3.5 \\
\hline 28 & $\mathrm{CH}_{3} \mathrm{~S}(\mathrm{O}) \mathrm{OO}+\mathrm{NO} \rightarrow \mathrm{CH}_{3} \mathrm{SO}_{2}+\mathrm{NO}_{2}$ & $8.0 \mathrm{E}-12$ & 3.5 \\
\hline 29 & $\mathrm{CH}_{3} \mathrm{~S}(\mathrm{O}) \mathrm{OO}+\mathrm{NO}_{2} \rightarrow \mathrm{CH}_{3} \mathrm{~S}(\mathrm{O}) \mathrm{OONO}_{2}$ & $1.0 \mathrm{E}-12$ & 3.5 \\
\hline 30 & $\mathrm{CH}_{3} \mathrm{~S}(\mathrm{O}) \mathrm{OONO}_{2} \rightarrow \mathrm{CH}_{3} \mathrm{~S}(\mathrm{O}) \mathrm{OO}+\mathrm{NO}_{2}$ & $4.2 \mathrm{E}-3$ & 3.5 \\
\hline 31 & $\mathrm{CH}_{3} \mathrm{SO}_{2}+\mathrm{NO}_{2} \rightarrow \mathrm{CH}_{3} \mathrm{SO}_{3}+\mathrm{NO}$ & $2.2 \mathrm{E}-12$ & 1.5 \\
\hline 32 & $\mathrm{CH}_{3} \mathrm{SO}_{2}+\mathrm{O}_{3} \rightarrow \mathrm{CH}_{3} \mathrm{SO}_{3}+\mathrm{O}_{2}$ & $5.0 \mathrm{E}-15$ & 3.5 \\
\hline 33 & $\mathrm{CH}_{3} \mathrm{SO}_{2}+\mathrm{OH} \rightarrow \mathrm{CH}_{3} \mathrm{SO}_{3} \mathrm{H}$ & $5.0 \mathrm{E}-11$ & 3.5 \\
\hline 34 & $\mathrm{CH}_{3} \mathrm{SO}_{2}+\mathrm{O}_{2} \rightarrow \mathrm{CH}_{3} \mathrm{~S}(\mathrm{O})_{2} \mathrm{OO}$ & $2.7 \mathrm{E}-14$ & 3.5 \\
\hline 35 & $\mathrm{CH}_{3} \mathrm{~S}(\mathrm{O})_{2} \mathrm{OO} \rightarrow \mathrm{CH}_{3} \mathrm{SO}_{2}+\mathrm{O}_{2}$ & $1.6 \mathrm{E} 5$ & 3.5 \\
\hline 36 & $\mathrm{CH}_{3} \mathrm{~S}(\mathrm{O})_{2} \mathrm{OO}+\mathrm{NO} \rightarrow \mathrm{CH}_{3} \mathrm{SO}_{3}+\mathrm{NO}_{2}$ & $1.0 \mathrm{E}-11$ & 3.5 \\
\hline 37 & $\mathrm{CH}_{3} \mathrm{~S}(\mathrm{O})_{2} \mathrm{OO}+\mathrm{CH}_{3} \mathrm{O}_{2} \rightarrow \mathrm{CH}_{3} \mathrm{SO}_{3}+\mathrm{CH}_{2} \mathrm{O}+\mathrm{HO}_{2}$ & $5.5 \mathrm{E}-12$ & 3.5 \\
\hline 38 & $\mathrm{CH}_{3} \mathrm{~S}(\mathrm{O})_{2} \mathrm{OO}+\mathrm{NO}_{2} \rightarrow \mathrm{CH}_{3} \mathrm{~S}(\mathrm{O})_{2} \mathrm{OONO}_{2}$ & $1.0 \mathrm{E}-12$ & 3.5 \\
\hline 39 & $\mathrm{CH}_{3} \mathrm{~S}(\mathrm{O})_{2} \mathrm{OONO}_{2} \rightarrow \mathrm{CH}_{3} \mathrm{~S}(\mathrm{O})_{2} \mathrm{OO}+\mathrm{NO}_{2}$ & $4.2 \mathrm{E}-3$ & 3.5 \\
\hline 40 & $\mathrm{CH}_{3} \mathrm{SO}_{2} \rightarrow \mathrm{CH}_{3}+\mathrm{SO}_{2}$ & 164 & 3.5 \\
\hline 41 & $\mathrm{CH}_{3} \mathrm{SO}_{3} \rightarrow \mathrm{CH}_{3}+\mathrm{SO}_{3}$ & 0.16 & 3.5 \\
\hline 42 & $\mathrm{CH}_{3} \mathrm{SO}_{3}+\mathrm{HO}_{2} \rightarrow \mathrm{CH}_{3} \mathrm{SO}_{3} \mathrm{H}+\mathrm{O}_{2}$ & $5.0 \mathrm{E}-11$ & 3.5 \\
\hline 43 & $\mathrm{SO}_{2}+\mathrm{OH} \rightarrow \mathrm{HOSO}_{2}$ & $9.2 \mathrm{E}-13$ & 1.5 \\
\hline 44 & $\mathrm{HOSO}_{2}+\mathrm{O}_{2} \rightarrow \mathrm{SO}_{3}+\mathrm{HO}_{2}$ & $4.1 \mathrm{E}-13$ & 1.2 \\
\hline 45 & $\mathrm{SO}_{3}+\mathrm{H}_{2} \mathrm{O} \rightarrow \mathrm{H}_{2} \mathrm{SO}_{4}$ & $1.6 \mathrm{E}-13$ & 2.0 \\
\hline 46 & $\mathrm{CH}_{3} \mathrm{SOO} \rightarrow \mathrm{CH}_{3} \mathrm{SO}_{2}$ & 1.0 & 3.5 \\
\hline 47 & $\mathrm{CH}_{3} \mathrm{~S}(\mathrm{O}) \mathrm{OO} \rightarrow \mathrm{CH}_{3} \mathrm{SO}_{3}$ & 4.0E-2 & 3.5 \\
\hline 48 & $\mathrm{CH}_{3} \mathrm{~S}(\mathrm{O}) \mathrm{OH} \rightarrow \mathrm{CH}_{3} \mathrm{SO}_{3} \mathrm{H}$ & $1.0 \mathrm{E}-6$ & 3.5 \\
\hline 49 & $\mathrm{CH}_{3} \mathrm{SOH} \rightarrow \mathrm{CH}_{3} \mathrm{SO}_{3} \mathrm{H}$ & $3.5 \mathrm{E}-5$ & 3.5 \\
\hline \multicolumn{4}{|c|}{ Non-Gas-Phase Processes } \\
\hline 50 & $\mathrm{CH}_{3} \mathrm{~S}(\mathrm{O}) \mathrm{CH}_{3} \rightarrow$ heterogeneous loss & $2.0 \mathrm{E}-4$ & 3.5 \\
\hline 51 & $\mathrm{CH}_{3} \mathrm{~S}(\mathrm{O})_{2} \mathrm{CH}_{3} \rightarrow$ heterogeneous loss & $2.0 \mathrm{E}-4$ & 3.5 \\
\hline 52 & $\mathrm{CH}_{3} \mathrm{SOH} \rightarrow$ heterogeneous loss & $2.0 \mathrm{E}-5$ & 3.5 \\
\hline 53 & $\mathrm{CH}_{3} \mathrm{SO}_{2} \mathrm{H} \rightarrow$ heterogeneous loss & $2.0 \mathrm{E}-5$ & 3.5 \\
\hline 54 & $\mathrm{CH}_{3} \mathrm{SO}_{3} \mathrm{H} \rightarrow$ heterogeneous loss & $2.5 \mathrm{E}-4$ & 3.5 \\
\hline 55 & $\mathrm{SO}_{2} \rightarrow$ heterogeneous loss & $5.0 \mathrm{E}-5$ & 3.5 \\
\hline 56 & $\mathrm{H}_{2} \mathrm{SO}_{4} \rightarrow$ heterogeneous loss & $1.0 \mathrm{E}-3$ & 3.5 \\
\hline 57 & DMS surface emission & $9.5 \mathrm{E} 4$ & 3.5 \\
\hline 58 & RMBL mixing coefficient & $2.5 \mathrm{E}-5$ & 1.5 \\
\hline
\end{tabular}


also includes a pathway that produces $\mathrm{H}_{2} \mathrm{SO}_{4}$ without involving $\mathrm{SO}_{2}$. This pathway has been noted before (Bandy et al., 1992; Lin and Chameides, 1993), but is often assumed to be inefficient due to the relatively fast dissociation of $\mathrm{CH}_{3} \mathrm{SO}_{2}$ (Kukui et al., 2000) and low levels of $\mathrm{CH}_{3} \mathrm{SO}_{3}$. The mechanism in Table 1, however, includes the following reactions that enhance $\mathrm{CH}_{3} \mathrm{SO}_{3}$ while bypassing $\mathrm{CH}_{3} \mathrm{SO}_{2}$ :

$$
\mathrm{CH}_{3} \mathrm{SO}+\mathrm{O}_{2} \rightleftharpoons \mathrm{CH}_{3} \mathrm{~S}(\mathrm{O}) \mathrm{OO} \longrightarrow \mathrm{CH}_{3} \mathrm{SO}_{3} .
$$

The isomerization step above is unique to our mechanism (see Lucas and Prinn, 2002). The net effects of the above pathway are increases in the levels of MSA and $\mathrm{H}_{2} \mathrm{SO}_{4}$ and a slight decrease in the concentration of $\mathrm{SO}_{2}$. The above pathway also increases the production of $\mathrm{H}_{2} \mathrm{SO}_{4}$ in the absence of $\mathrm{OH}$ at night after DMS reacts with $\mathrm{NO}_{3}$.

The $\mathrm{OH}$-addition branch of the DMS+OH reaction has a negative temperature-dependence, and is the dominant path at temperatures below about $275 \mathrm{~K}$. The key branching points along this path occur at $\mathrm{OH}$ addition adducts that either react with $\mathrm{O}_{2}$ to form DMSO and $\mathrm{DMSO}_{2}$ or dissociate into MSEA and MSIA. These reactions are summarized below (for $x=0$ and 1):

$$
\begin{aligned}
\mathrm{CH}_{3} \mathrm{~S}(\mathrm{O})_{x}(\mathrm{OH}) \mathrm{CH}_{3} \stackrel{+\mathrm{O}_{2}}{\longrightarrow} \mathrm{CH}_{3} \mathrm{~S}(\mathrm{O})_{x+1} \mathrm{CH}_{3}+\mathrm{HO}_{2} \\
\longrightarrow \mathrm{CH}_{3} \mathrm{~S}(\mathrm{O})_{x} \mathrm{OH}+\mathrm{CH}_{3} .
\end{aligned}
$$

The MSEA and MSIA formed in the dissociation branch are rapidly attacked by $\mathrm{OH}$ to produce $\mathrm{CH}_{3} \mathrm{SO}_{\mathrm{x}}$ radicals as shown by the following reaction (for $x=0$ and 1 ):

$$
\mathrm{CH}_{3} \mathrm{~S}(\mathrm{O})_{x} \mathrm{OH}+\mathrm{OH} \longrightarrow \mathrm{CH}_{3} \mathrm{SO}_{x+1}+\mathrm{H}_{2} \mathrm{O} \text {. }
$$

The resulting $\mathrm{CH}_{3} \mathrm{SO}_{\mathrm{x}}$ radicals can then react or dissociate to form MSA, $\mathrm{SO}_{2}$ and $\mathrm{H}_{2} \mathrm{SO}_{4}$ as previously described. The above reaction, therefore, serves as a cross-over point from the $\mathrm{OH}$-addition branch to the $\mathrm{H}$-abstraction branch. Given the potential importance of these reactions, we have updated the rate constant for the above MSIA+OH reaction based on new experimental evidence by Kukui et al. (2003). We have also added two similar reactions (see reactions 15 and 16 in Table 1) that convert MSEA to $\mathrm{CH}_{3} \mathrm{SO}$ by $\mathrm{HO}_{2}$ and $\mathrm{CH}_{3} \mathrm{O}_{2}$ using the rate constants in Yin et al. (1990).

Lastly, we note that the production of MSA is highly uncertain and believed to occur through both the $\mathrm{H}$-abstraction and $\mathrm{OH}$-addition channels. In this model, MSA is explicitly produced through the $\mathrm{H}$-abstraction branch by:

$$
\mathrm{CH}_{3} \mathrm{SO}_{3}+\mathrm{HO}_{2} \longrightarrow \mathrm{CH}_{3} \mathrm{SO}_{3} \mathrm{H}+\mathrm{O}_{2} .
$$

In Lucas and Prinn (2002) it was shown that the above reaction alone is not sufficient to produce the levels of MSA observed in the RMBL, and it was argued that production through the $\mathrm{OH}$-addition path involving MSEA and/or MSIA is likely. Other studies have suggested similar production routes (see Hatakeyama and Akimoto, 1983; Koga and Tanaka, 1993), but the details of these pathways are currently not known. We therefore use the following parameterized first-order conversions (represented by dashed arrows) to produce MSA from MSEA and MSIA:

$$
\begin{aligned}
& \mathrm{CH}_{3} \mathrm{SOH} \rightarrow-\rightarrow \mathrm{CH}_{3} \mathrm{SO}_{3} \mathrm{H} \\
& \mathrm{CH}_{3} \mathrm{~S}(\mathrm{O}) \mathrm{OH} \rightarrow-\rightarrow \mathrm{CH}_{3} \mathrm{SO}_{3} \mathrm{H} .
\end{aligned}
$$

The paths tested in Lucas and Prinn (2002) were used to estimate the rates of the above first-order, parameterized conversions.

\subsubsection{Heterogeneous removal}

Heterogeneous removal is formally estimated using $p_{h}=p_{a}+p_{d}$, where $p_{a}$ and $p_{d}$ are loss frequencies due to scavenging by aerosols and dry deposition at the ocean surface, respectively. Scavenging by aerosols dominates the net heterogeneous removal for most of the DMS oxidation products (i.e. $p_{h} \approx p_{a}$ ). For $\mathrm{SO}_{2}$, however, both losses are important. The aerosol loss frequencies $\left(p_{a}\right)$ are averages over the boundary layer portions of the observationallybased vertical scavenging profiles in Lucas and Prinn (2002), while the dry deposition losses $\left(p_{d}\right)$ are set using typical dry deposition velocities for a stable RMBL. The $p_{h}$ for $\mathrm{SO}_{2}$ is taken as the empirically-derived removal frequency noted in Lucas and Prinn (2002). The net $p_{h}$ values are listed in Table 1.

\subsubsection{RMBL mixing}

Transport into or out of the RMBL is parameterized as the product of a first-order mixing coefficient $\left(p_{m}\right)$ and the vertical concentration difference between the boundary layer and free troposphere $(\Delta n)$. We estimate the mixing coefficient from the scaling $\partial / \partial z\left(K_{z} \partial n / \partial z\right) \sim p_{m} \Delta n$, where $K_{z}$ is the vertical eddy-diffusion coefficient. This leads to $p_{m} \approx K_{z} /(\Delta z)^{2}$ for a mixing depth scale of $\Delta z$. The specific mean value of $p_{m}=2.5 \times 10^{-5} \mathrm{~s}^{-1}$ is estimated from $K_{z}=6.25 \mathrm{~m}^{2} \mathrm{~s}^{-1}$ and $\Delta z=500 \mathrm{~m}$, which are representative values for the stable marine atmosphere. The RMBL mixing approximation is applied to $\mathrm{DMS}, \mathrm{SO}_{2}$ and MSA because these species had large observed vertical gradients during the measurement campaign used to define the background conditions in the model (see Sect. 2.2). The remaining sulfur-containing species are assumed to have no vertical concentration gradients. For simplicity and consistency, the free tropospheric concentrations of DMS, $\mathrm{SO}_{2}$ and MSA are fixed in time and based on the observed or modeled values at the interface between the "buffer layer" and free troposphere in Lucas and Prinn (2002). These values are set as $5.0 \times 10^{7}, 2.2 \times 10^{9}$, and $4.5 \times 10^{6}$ molecules $\mathrm{cm}^{-3}$, respectively, for DMS, $\mathrm{SO}_{2}$ and MSA. 
Table 2. Background conditions used in the DMS chemistry model. Each condition is "fixed" or "varies" with time as noted. The values are either based on measurements from ACE-1 Flight 24, diagnosed from the measurements, or assumed.

\begin{tabular}{llll}
\hline & Value & Time & Source \\
\hline mixed layer depth & $500 \mathrm{~m}$ & fixed & measured \\
temperature & $287 \mathrm{~K}$ & fixed & measured \\
pressure & $980 \mathrm{hPa}$ & fixed & measured \\
relative humidity & $75 \%$ & fixed & measured \\
$\mathrm{O}_{3}$ & $20 \mathrm{ppb}$ & fixed & measured \\
$\mathrm{OH}$ & see Fig. 2 & varies & measured \\
$\mathrm{HO}_{2}, \mathrm{CH}_{3} \mathrm{O}_{2}, \mathrm{NO}_{2}, \mathrm{NO}_{3}$ & see Fig. 2 & varies & diagnosed \\
$\mathrm{NO}$ & $1 \mathrm{ppt}$ & fixed & assumed \\
\hline
\end{tabular}

\subsubsection{DMS emissions}

DMS emissions are usually calculated using surface wind speeds and DMS sea surface concentrations. For the sake of simplicity, however, we assume a mean value for the oceanic emission rate of $p_{e}=9.5 \times 10^{4}$ molecules $\mathrm{cm}^{-3} \mathrm{~s}^{-1}$. This emission rate is based on our previous estimate in the RMBL of the Southern Ocean (Lucas and Prinn, 2002). For a mixed layer depth of $500 \mathrm{~m}$, the corresponding DMS surface flux is comparable to the flux values of Bates et al. (1998b), Mari et al. (1999), and Shon et al. (2001). Note that the 2$\sigma$ uncertainty range for the DMS emissions parameter extends from $7.8 \times 10^{3}$ to $1.2 \times 10^{6}$ molecules $\mathrm{cm}^{-3} \mathrm{~s}^{-1}$, which is larger than the range considered in Capaldo and Pandis (1997) (i.e. $1.0 \times 10^{4}$ to $1.4 \times 10^{5}$ molecules $\mathrm{cm}^{-3} \mathrm{~s}^{-1}$ ).

\subsection{Background conditions in the RMBL}

The background meteorological and oxidizing conditions used in the box model are given in Table 2. These conditions are taken from the midpoint of the boundary layer in the 1-D model of Lucas and Prinn (2002), and are originally based on the observations from Flight 24 of the First Aerosol Characterization Experiment (ACE-1) (Bates et al., 1998a). The flight occurred during the austral summer in the clear sky over the Southern Ocean southwest of Tasmania. Five-day back trajectories indicated that the surface air masses were of a remote marine origin, and the region was characterized by relatively high DMS concentrations. The measurements were made between about 05:30 and 14:30 local time (LT), and sunrise and sunset occurred at 04:24 and 19:36 LT, respectively.

The important oxidizing-related species $\mathrm{OH}, \mathrm{O}_{3}, \mathrm{H}_{2} \mathrm{O}_{2}$ and $\mathrm{CH}_{3} \mathrm{OOH}$ were measured during the flight. As described in Lucas and Prinn (2002), the $\mathrm{OH}$ and peroxide measurements varied with time and were fit to time-dependent "forcing" functions. We use the $\mathrm{OH}$ forcing function and RMBLaverage $\mathrm{O}_{3}$ directly in the model to oxidize the sulfur-based species. The functional fits of the peroxides are used to di-

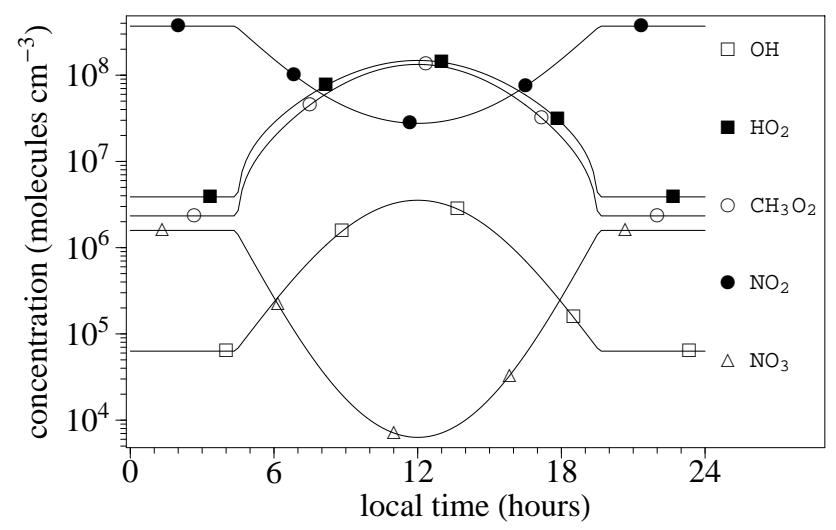

Fig. 2. Diurnal cycles of the radicals used to drive the DMS chemistry. The $\mathrm{OH}$ cycle is based on a fit to measurements and the other radicals are calculated diagnostically.

agnose the time-dependent concentrations of $\mathrm{NO}_{2}, \mathrm{HO}_{2}$, and $\mathrm{CH}_{3} \mathrm{O}_{2}$ assuming steady state chemistry.

Two additional oxidants (i.e. $\mathrm{NO}$ and $\mathrm{NO}_{3}$ ) are also required, but were not directly measured during the flight. NO was below the instrument detection limit of $1 \mathrm{ppt}$, so a constant mole fraction of $1 \mathrm{ppt}$ is assumed. For $\mathrm{NO}_{3}$, Allan et al. (1999) showed that its reaction with DMS is the primary sink in the summertime RMBL. Therefore, we estimate the time-dependent concentration of $\mathrm{NO}_{3}$ using a steady state balance between production from the $\mathrm{NO}_{2}+\mathrm{O}_{3}$ reaction and loss by photolysis during the day and by the reaction with DMS at night. These assumptions lead to approximate midday and nighttime $\mathrm{NO}_{3}$ concentrations of $6.3 \times 10^{3}$ and $1.6 \times 10^{6}$ molecules $\mathrm{cm}^{-3}$, respectively. By comparison, the nighttime $\mathrm{NO}_{3}$ levels used to oxidize DMS by Chen et al. (2000) for the remote equatorial Pacific are about three times lower. The resulting diurnal cycles of $\mathrm{OH}, \mathrm{HO}_{2}, \mathrm{NO}_{2}, \mathrm{NO}_{3}$ and $\mathrm{CH}_{3} \mathrm{O}_{2}$ are shown in Fig. 2.

We emphasize again that our focus is on a detailed sensitivity and uncertainty analysis at this single set of RMBL conditions. The conditions within the RMBL are highly variable, however, so an analysis at other conditions may yield different results. Capaldo and Pandis (1997), for instance, found important DMS chemistry variations across nine sets of RMBL conditions associated with different locations and seasons. Over their nine scenarios, temperature, $\mathrm{O}_{3}$ and the mixing height ranged between $283-300 \mathrm{~K}, 9-18 \mathrm{ppb}$, and 500-1800 meters, respectively. As an attempt to cover these large ranges, we assign relatively large uncertainties to many of the model parameters. For example, the majority of the rate constants have 2- $\sigma$ uncertainty ranges that are broader than their ranges across temperatures of 283 to $300 \mathrm{~K}$. Moreover, the 2- $\sigma$ uncertainty range for DMS emissions is wider than the emission rates across the nine scenarios in Capaldo and Pandis (1997). 


\subsection{Treatment of uncertainties}

A parametric analysis is our focus, as opposed to a structural analysis. The sources of uncertainty are therefore the values of the rate constants and other model parameters, not the set of processes representing the model. The uncertain model parameters are treated as independent random variables following lognormal probability distribution functions (PDFs). Lognormal parameter PDFs are used because they provide positive samples, which prevents non-physical negative values from entering the model. Because our analysis is in logarithmic space, we use the following notation

$$
\eta=\log n \text { and } \varrho=\log p,
$$

to denote log-scaled concentrations $(\eta)$ and parameters $(\varrho)$, respectively. Hereafter, the terms concentrations and parameters are used inter-changeably with logarithmic concentrations and parameters, though the specific context is apparent by the above notation.

Table 1 lists the mean values $(\bar{p})$ and uncertainties $(\phi)$ of the parameters, where the uncertainties are specified as multiplicative factors (i.e. $\bar{p} \times \phi$ and $\bar{p} \times 1 / \phi$ ). The values of the uncertainty factors are assigned as follows. Rate constant uncertainties have been reported for many of the laboratorymeasured rate constants (e.g. DeMore et al., 1997; Atkinson et al., 1997). We use these reported values, which range from $\phi=1.1$ to 2.0. For rate constants that are estimated, or those for which uncertainties were not reported, we assume $\phi=3.5$. This gives a $2-\sigma$ uncertainty range of a factor of 150 (i.e. $3.5^{4}$ ) for the highly-uncertain chemical reactions. We also assume uncertainty factors of 3.5 for the heterogeneous removal and DMS emission parameters because we do not want to bias the net concentration uncertainties as depending any more or less on these parameters relative to the gas-phase chemistry. Last, a comparatively smaller uncertainty is used for the vertical mixing parameter $(\phi=1.5)$ to maintain stable mixing conditions (i.e. keep $K_{z}$ below about $15 \mathrm{~m}^{2} \mathrm{~s}^{-1}$ for $\Delta z=500 \mathrm{~m})$.

We also note that the assumption of independent random variables is suitable for the chemical rate constants because their values are generally not related. This assumption may not hold for the physical parameters, however (e.g. turbulent mixing and DMS emissions are connected through surface wind forcing). As a first approximation, we assume the physical parameters vary independently because they are influenced by many isolated factors (e.g. the heterogeneous removal parameters depend on species-specific mass accommodation coefficients).

\section{Sensitivity and uncertainty analysis methods}

The DMS oxidation cycle in the RMBL is a complex system with large diurnal variations and many large sources of uncertainty. We therefore apply two different sensitivity and uncertainty methods to characterize these aspects of the DMS cycle. We use a local sensitivity method that conveniently assesses time-dependent local sensitivities and a global sensitivity and uncertainty method that is better suited for quantifying the effects of the many large sources of uncertainty. The two methods and their advantages and disadvantages are described below.

\subsection{Local sensitivity analysis - direct integration method}

For the local sensitivity analysis we use the direct integration method (DIM), which is a standard technique that has been used for sensitivity studies over the past three decades (e.g. Dickinson and Gelinas, 1976). The goal of the local sensitivity analysis is to quantify the changes to the sulfurbased concentrations for infinitesimal changes in the model parameters. This analysis is useful for examining model behavior and identifying critical model parameters, but only at a specified local set of parameter values. Uncertainty-related information does not enter directly into the local sensitivity analysis. Uncertainties are instead analyzed using a global method (see Sect. 3.2).

Before deriving the sensitivity equations, we initially define the first-order local sensitivity coefficient of concentration $n_{i}$ to model parameter $p_{j}$ as

$$
z_{i j}=\frac{\partial n_{i}}{\partial p_{j}}
$$

Our model parameters have different units, so we apply the following normalization

$$
\frac{\partial \eta_{i}}{\partial \varrho_{j}}=\frac{\partial \log n_{i}}{\partial \log p_{j}}=\frac{p_{j}}{n_{i}} z_{i j},
$$

using the log-scaled concentrations and parameters from Eq. (2). The normalized local sensitivities are unitless and describe the fractional changes to the concentrations for fractional changes to the parameters.

The sensitivity equations are derived by differentiating Eq. (1) with respect to parameter $p_{j}$ as in

$$
\frac{\partial}{\partial p_{j}}\left(\frac{d n_{i}}{d t}=\dot{n}_{i}\right),
$$

where $\dot{n}_{i}$ represents the right hand side of Eq. (1). The order of differentiation is interchanged on the left hand side and the chain rule applied on the right hand side. This leads to the following time-dependent system of ODEs in terms of $z_{i j}$

$$
\frac{d z_{i j}}{d t}=\frac{\partial \dot{n}_{i}}{\partial p_{j}}+\sum_{k=1}^{N}\left(\frac{\partial \dot{n}_{i}}{\partial n_{k}} z_{k j}\right),
$$

where $N$ is the number of sulfur-containing species in our model (i.e. $N=25$ ). The first-order local sensitivity analysis using DIM proceeds by integrating the concentration 
ODEs in Eq. (1) and first-order local sensitivity ODEs in Eq. (6). Combined, the first-order local analysis solves for 1475 ODEs.

For sensitivity and uncertainty analyses, DIM has two drawbacks. First, DIM is a local method because a single DIM run produces sensitivity information at only one set of points in the uncertainty space of the model parameters. Local sensitivities often vary significantly within the parameter uncertainty space, however, as noted by Saltelli (1999). This limits DIM's effectiveness for estimating model output uncertainties. For example, uncertainties in $\eta_{i}$ are often extrapolated from first-order local sensitivities using

$$
\sigma_{\eta_{i}}^{2} \approx \sum_{j=1}^{M}\left(\frac{\partial \eta_{i}}{\partial \varrho_{j}}\right)^{2} \sigma_{j}^{2},
$$

where $\sigma_{\eta_{i}}^{2}$ and $\sigma_{j}^{2}$ are the variances of $\eta_{i}$ and $\varrho_{j}$, respectively, and the summation is over $M$ parameters. We show later in Sect. 4.2.3 that some of the $\partial \eta_{i} / \partial \varrho_{j}$ in our DMS model vary by more than a factor of 2 across the $1-\sigma$ uncertainty range of parameter $\varrho_{j}$. For this reason, we do not use DIM in the uncertainty analysis.

As another drawback, DIM is typically restricted to firstorder sensitivity studies because higher-order sensitivities, acquired by further differentiation of Eq. (6), lead to large systems of equations. The second-order sensitivity system for our DMS model, for example, has 44250 ODEs. Because interactions between parameters and other higher-order effects are important in the DMS cycle, higher-order sensitivity coefficients are instead calculated using the global method described in Sect. 3.2.

In spite of these drawbacks, DIM is convenient for analyzing local sensitivities as a function of time because Eq. (6) has the same structure as Eq. (1). The same algorithm is therefore used to simultaneously advance the numerical solutions to the concentration ODEs and first-order local sensitivity ODEs. For this study, we use the Ordinary Differential Equation Solver With Explicit Simultaneous Sensitivity Analysis algorithm from Leis and Kramer (1988a,b). The algorithm is a stiff ODE solver appropriate for models containing atmospheric chemistry and it has a built-in capability for performing a first-order local sensitivity analysis.

\subsection{Global analysis - probabilistic collocation method}

In contrast to the local sensitivity analysis, the global sensitivity and uncertainty analysis covers the full uncertainty ranges of the parameters. The primary goals of the global analysis are to quantify the net uncertainties in the sulfurbased concentration predictions and to identify and rank the parameter-based contributions to the net uncertainties. Towards these goals, we utilize the probabilistic collocation method (PCM) (Tatang et al., 1997).

PCM is one of many available global methods that quantifies and decomposes uncertainties in complex models (e.g. see Saltelli et al., 2000). For some models, PCM offers the benefits of a full Monte Carlo analysis, but at highly-reduced computational costs. A detailed description of PCM and its comparison to the Monte Carlo method are given in Tatang et al. (1997). For applications, PCM has been used in uncertainty analyses of highly non-linear models of direct and indirect aerosol radiative forcing (Pan et al., 1997, 1998). PCM has also been used to create numerically-efficient parameterizations of non-linear chemical processing in an urban-scale model (Calbó et al., 1998; Mayer et al., 2000).

As a brief outline of the methodology, PCM approximates the outputs of a model using expansions of orthogonal polynomials of the model inputs. The model inputs are cast as random variables, where each input parameter is defined by a PDF. The input PDFs serve as weighting functions in recursive relationships used to generate the orthogonal polynomials, the roots of which are also used to define sets of collocation points. The coefficients of the expansions are determined by running the model at these sets of collocation points. The resulting model output expansions are polynomial chaos expansions (PCEs) fit to the true model output surface and weighting the high probability regions of the model inputs. We use the Deterministic Equivalent Modeling Method Using Collocation and Monte Carlo package (Tatang, 1995) to construct the orthogonal polynomials, determine the collocation points, and perform the numerical fits.

As applied to sensitivity and uncertainty studies, PCM has numerous advantages and two disadvantages worth noting. The major advantage is that PCM characterizes the sensitivities and uncertainties throughout the uncertainty domain of the model parameters. PCM is thus a global method that quantifies the contributions of uncertain inputs to the uncertain outputs. Three other advantages are related to the polynomial representation used by PCM. First, the PCEs are structured so that the squares of the coefficients are directly proportional to the variance of the outputs, which makes it straightforward to identify and rank the sources of uncertainty. Second, provided they correlate well with the original model, the PCEs are computationally very efficient versions of the true model because evaluating polynomials is far more efficient than, for example, solving ODEs. Third, higherorder analyses, including parameter interactions, are readily assessable through the coefficients of the higher-order terms in the PCEs (at no additional computational costs).

The following two disadvantages should also be keep in mind in a PCM analysis. PCM can be even more expensive than brute-force Monte Carlo for highly non-linear models with many uncertain inputs. Using the DMS model as an example, a full third-order PCE for 58 inputs requires 35990 model runs to fit the coefficients, while a full secondorder PCE requires only 1770 . Also, to analyze time-varying model outputs, either PCEs must be generated at each time of interest or an input random variable for "time" must be introduced (e.g. using a uniform PDF). These methods, however, 
are cumbersome or difficult for models with very large time variations.

\subsubsection{Application of PCM to the DMS model}

The inputs to PCM are the 58 uncertain model parameters listed in Table 1 . We use the log-scaled forms of the parameters (i.e. $\varrho$ ) and treat them as Gaussian random variables. These are transformed to standard Gaussian random variables $\xi$ with a mean of zero and variance of one using

$$
\xi_{k}=\left(\varrho_{k}-\bar{\varrho}_{k}\right) / \sigma_{k}
$$

where $\varrho_{k}$ is the $k$-th model parameter, and $\bar{\varrho}_{k}$ and $\sigma_{k}$ are its mean value and standard deviation. The PDFs of $\xi_{k}$ serve as weight functions to generate the orthogonal polynomial basis for the polynomial chaos expansions. For standard normal PDFs, the corresponding orthogonal polynomials are the Hermite polynomials in Table 3. As detailed in Xiu and Karniadakis (2003), different random variables lead to different orthogonal polynomials used in PCEs (e.g. uniformly distributed random variables correspond with Legendre polynomials).

The log-scaled sulfur-containing concentrations are then expressed by polynomial chaos expansions of the Hermite polynomials in terms of $\xi$. To maintain reasonably-sized expansions, the PCEs calculated here include homogeneous (pure) terms up to cubic order and all possible 2nd-order heterogeneous (cross) terms. The resulting expansions have 1828 coefficients. Separate PCEs were generated for DMS, $\mathrm{SO}_{2}, \mathrm{MSA}$, and $\mathrm{H}_{2} \mathrm{SO}_{4}$. Each PCE has the form $(M=58)$

$$
\begin{aligned}
\hat{\eta}=\alpha_{0}+\sum_{j=1}^{3} \sum_{k=1}^{M} \alpha_{j, k} H_{j}\left(\xi_{k}\right) & \\
& +\sum_{k=1}^{M-1} \sum_{\ell=k+1}^{M} \beta_{k, \ell} H_{1}\left(\xi_{k}\right) H_{1}\left(\xi_{\ell}\right),
\end{aligned}
$$

where $\hat{\eta}$ approximates the concentration from the true model (i.e. $\hat{\eta} \approx \eta), \alpha_{0}$ is the zeroth-order coefficient, $\alpha_{j, k}$ is the $j$-th order coefficient of the $k$-th parameter, $\beta_{k, \ell}$ is the coefficient of the 2 nd-order cross term between input parameters $k$ and $\ell$, and $H_{j}\left(\xi_{k}\right)$ is the $j$-th order Hermite polynomial for the standard random input parameter $\xi_{k}$. The coefficients in Eq. (9) are computed from 1828 runs of Eq. (1) at the input parameter collocation points, which are chosen from the roots of the Hermite polynomials.

We fit to log-scaled concentrations above for two reasons. First, the solutions to chemical ODEs involve exponential functions, so log-scaling removes much of the exponential behavior and allows for better fits with lower-order polynomials. Second, lognormally distributed random variables naturally result from products of random variables, which are represented by the higher-order terms in the PCEs.
Table 3. Hermite polynomials in terms of a standard Gaussian random variable $\xi$. The expected values of the Hermite polynomials are also given (see Eq. 13 in Sect. 3.2.3).

\begin{tabular}{ccccc}
\hline Order & Hermite Polynomial & $E\left[H_{j}\right]$ & $E\left[H_{j}^{2}\right]$ & $E\left[H_{j}^{3}\right]$ \\
\hline 0 & $H_{0}=1$ & 1 & 1 & 1 \\
1 & $H_{1}=\xi$ & 0 & 1 & 0 \\
2 & $H_{2}=\xi^{2}-1$ & 0 & 2 & 8 \\
3 & $H_{3}=\xi^{3}-3 \xi$ & 0 & 6 & 0 \\
4 & $H_{4}=\xi^{4}-6 \xi^{2}+3$ & 0 & 24 & 1728 \\
\hline
\end{tabular}

\subsubsection{Local sensitivities using PCM}

PCM is a global method, but by differentiating the PCEs with respect to the model parameters PCM also provides local sensitivity information. This technique is useful for comparing the results between PCM and DIM, and for illustrating certain deficiencies in DIM.

The first-order local sensitivity coefficients using PCM are obtained by differentiating Eq. (9) with respect to $\varrho_{q}$. This yields

$$
\frac{\partial \hat{\eta}}{\partial \varrho_{q}} \sigma_{q}=\alpha_{1, q}+2 \alpha_{2, q} \xi_{q}+3 \alpha_{3, q}\left(\xi_{q}^{2}-1\right)+\sum_{\substack{k=1 \\ k \neq q}}^{M} \beta_{k, q} \xi_{k}
$$

where $\sigma_{q}$ is the standard deviation of $\varrho_{q}$. We use this expression in two ways. First, we set $\xi$ to zero, which gives the first-order local sensitivities at the parameter means and provides a way to directly compare to the DIM-based values from Eq. (6). Second, we evaluate Eq. (10) over $|\xi| \leq 1$. This analysis shows that many of the first-order local sensitivities in the DMS cycle vary dramatically in the parameter uncertainty spaces, and thus using Eq. (7) to extrapolate concentration uncertainties can lead to large errors.

It is straightforward to derive higher-order local sensitivity coefficients by further differentiation of Eq. (10). Doing so, the second- and third-order local sensitivity coefficients are

$$
\begin{aligned}
& \frac{\partial^{2} \hat{\eta}}{\partial \varrho_{q}^{2}} \sigma_{q}^{2}=2 \alpha_{2, q}+6 \alpha_{3, q} \xi_{q}, \quad \frac{\partial^{2} \hat{\eta}}{\partial \varrho_{q} \partial \varrho_{r}} \sigma_{q} \sigma_{r}=\beta_{q, r}, \text { and } \\
& \frac{\partial^{3} \hat{\eta}}{\partial \varrho_{q}^{3}} \sigma_{q}^{3}=6 \alpha_{3, q} .
\end{aligned}
$$

These higher-order local sensitivities are evaluated to gauge the importance of interactions between model processes and other non-linearities. The presence of large higher-order sensitivities signals additional shortcomings in Eq. (7), which uses only first-order terms to extrapolate concentration uncertainties.

Lastly, the local sensitivities in Eqs. (10) and (11) are weighted by the standard deviations of the parameters. This 
implies a relationship between concentrations uncertainties on the left hand side and the PCE coefficients on the right hand side. This relationship is formally derived in the next section by taking the expected values of the PCEs.

\subsubsection{Global sensitivities and uncertainties using PCM}

The global analysis propagates the uncertain parameters through the model and characterizes the statistical properties of the uncertain sulfur-containing concentrations. We use the PCEs in Eq. (9) for this analysis. The PCEs could be evaluated over many random samples of the inputs (i.e. $\xi$ ), thus generating concentration PDFs that could then be assessed using standard statistical methods.

Instead, we extract important statistical properties of $\hat{\eta}$ directly from the PCEs by taking expected values of Eq. (9). The mean value $\langle\hat{\eta}\rangle$, variance $\sigma_{\hat{\eta}}^{2}$, and skewness $\gamma_{\hat{\eta}}$, for instance, are determined from

$$
\begin{aligned}
& \langle\hat{\eta}\rangle=E[\hat{\eta}], \quad \sigma_{\hat{\eta}}^{2}=E\left[(\hat{\eta}-\langle\hat{\eta}\rangle)^{2}\right], \quad \text { and } \\
& \gamma_{\hat{\eta}}=E\left[(\hat{\eta}-\langle\hat{\eta}|)^{3}\right] / \sigma_{\hat{\eta}}^{3},
\end{aligned}
$$

where $E[$ ] denotes an expected value. For multivariate random variables, as in $\hat{\eta}\left(\xi_{1}, \xi_{2}, \ldots\right)$, expected values generally require multidimensional integrations. The expected values of $\hat{\eta}$, however, are decomposed using $E[a X]=a E[X]$, $E[X+Y]=E[X]+E[Y]$, and $E[X Y]=E[X] E[Y]$ for random variables $X$ and $Y$ and constant $a$, where the last property holds for independent variables. The expected values of Eq. (9) therefore simplify into sums and products of

$$
E\left[H_{j}^{m}\right]=\frac{1}{\sqrt{2 \pi}} \int_{-\infty}^{\infty} H_{j}^{m}(\xi) e^{-\xi^{2} / 2} d \xi
$$

which is the expected value of the $j$-th order univariate Hermite polynomial raised to the $m$-th power for a standard Gaussian PDF. The relevant values of Eq. (13) are given in Table 3.

The mean values of the sulfur-containing concentrations are derived from $E[\hat{\eta}]$. Referring to Table 3 , all of the $E\left[H_{j}\right]$ are zero except for $E\left[H_{0}\right]$, and so the mean values are simply the leading coefficients of the PCEs, i.e.

$$
\langle\hat{\eta}\rangle=\alpha_{0}
$$

The concentration variances are calculated by taking the expected value of $\left(\hat{\eta}-\alpha_{0}\right)^{2}$. Using Table 3 , it is easy to show that the only non-zero expected values occur for the $H_{j}^{2}$ terms. Thus, the variance of Eq. (9) is

$$
\sigma_{\hat{\eta}}^{2}=\sum_{j=1}^{M}\left(\alpha_{1, j}^{2}+2 \alpha_{2, j}^{2}+6 \alpha_{3, j}^{2}\right)+\sum_{j=1}^{M-1} \sum_{k=j+1}^{M} \beta_{j, k}^{2} .
$$

This expression is a quantitative measure of the net uncertainties in the sulfur-based concentrations resulting from the uncertain model parameters. As shown, the net concentration uncertainties are directly proportional to the squares of the PCE coefficients. This measure also covers the full probabilistic space of the uncertain parameters (i.e. Eq. 13) and includes higher-order and cross-term contributions. Moreover, the above summations are over parameter indices. Eq. (15) thus provides a quantitative way to allocate the contributions of the parameter-based sources of uncertainty (i.e. the global sensitivities). Of the total uncertainty, the uncertainty contribution (UC) of parameter $q$ is given by

$$
\mathrm{UC}_{q}=\alpha_{1, q}^{2}+2 \alpha_{2, q}^{2}+6 \alpha_{3, q}^{2}+\sum_{\substack{k=1 \\ k \neq q}}^{M} \frac{\beta_{k, q}^{2}}{2} .
$$

Note that the cross term contributions $\beta_{k, q}^{2}$ are divided by two to evenly split the contribution between the two parameters because $\xi_{k}$ and $\xi_{q}$ have the same variance.

Higher-order expected values of $\hat{\eta}$ can also be calculated using the same technique, but are increasingly more complicated. To illustrate, the skewness of Eq. (9) is obtained from the expected value of $\left(\hat{\eta}-\alpha_{0}\right)^{3}$, which results in

$$
\begin{aligned}
& \gamma_{\hat{\eta}}=\frac{1}{\sigma_{\hat{\eta}}^{3}}\left\{\sum_{j=1}^{M} \alpha_{2, j}\left[3 \alpha_{1, j}^{2}+8 \alpha_{2, j}^{2}+3\left(\alpha_{1, j}+6 \alpha_{3, j}\right)^{2}\right]\right. \\
& +6 \sum_{j=1}^{M-1} \sum_{k=j+1}^{M}\left[\beta_{j, k} \alpha_{1, j} \alpha_{1, k}+\beta_{j, k}^{2}\left(\alpha_{2, j}+\alpha_{2, k}\right)\right] \\
& \left.+6 \sum_{j=1}^{M-2} \sum_{k=j+1}^{M-1} \sum_{\ell=k+1}^{M} \beta_{j, k} \beta_{j, \ell} \beta_{k, \ell}\right\} .
\end{aligned}
$$

We use this expression to compute the asymmetries in the concentrations about their mean values.

\section{Results and discussion}

The concentrations of the sulfur-containing species are solved by integrating Eq. (1) for ten days using the stiff ODE solver. By the final day, repetitive diurnal cycles are achieved for all of the species. The following analysis is for the final day of this integration. To provide contrast between periods of inactive and active chemistry, the global sensitivity and uncertainty analysis using PCM is carried out at 04:00 LT (pre-sunrise) and 12:00 LT (midday).

\subsection{Concentrations}

\subsubsection{Diurnal concentration cycles}

The diurnal cycles of DMS, $\mathrm{SO}_{2}$, MSA, and $\mathrm{H}_{2} \mathrm{SO}_{4}$ are displayed in Fig. 3 for the mean values of the parameters. These simulated cycles follow the boundary layer observations analyzed in Lucas and Prinn (2002). The DMS and $\mathrm{SO}_{2}$ cycles have small amplitudes with peaks shifted away from noon 
because they are strongly influenced by non-photochemical processes. The MSA and $\mathrm{H}_{2} \mathrm{SO}_{4}$ cycles, on the other hand, have large amplitudes and peak near local noon because their net daytime sources are dominated by chemistry. The individual source and sink terms affecting these concentration cycles are shown later in Sect. 4.2.1.

Also note that the DMS and $\mathrm{SO}_{2}$ cycles are strongly anticorrelated. This anti-correlation has been both observed and modeled in the RMBL (Davis et al., 1999; Chen et al., 2000), and serves as primary evidence that $\mathrm{SO}_{2}$ in the marine environment is photochemically produced from DMS oxidation. The phases of the DMS and $\mathrm{SO}_{2}$ cycles in Fig. 3 match the cycles modeled for tropical Pacific conditions by Davis et al. (1999) and Chen et al. (2000); in particular their maxima and minima occur at roughly the same times. Our diurnal amplitudes for DMS and $\mathrm{SO}_{2}$, however, are smaller than in Davis et al. (1999) and Chen et al. (2000), due in part to differing strengths of the $\mathrm{OH}$ cycle.

\subsubsection{Concentration correlations}

PCM is a useful global sensitivity and uncertainty method only if the polynomial chaos expansions of the model outputs are good representations of the true model outputs. We test the quality of the PCEs by comparing the concentrations from Eq. (9) with those from Eq. (1) for $10^{3}$ common sets of randomly sampled parameters. These concentration correlations are shown in Fig. 4 at 04:00 LT and 12:00 LT. Also shown are the 1:1 lines, indices of agreement $(d)$ and coefficients of determination $\left(R^{2}\right)$, where the $R^{2}$ terms denote the amount of variance of the true model captured by the PCEs.

As indicated in the figure, the concentrations from the true model and PCEs are highly correlated for the four species. The correlations for MSA and $\mathrm{H}_{2} \mathrm{SO}_{4}$ even hold over four to five orders of magnitude. For a given species, the correlations are also similar at the two times, except for MSA, which has a stronger correlation at 04:00 LT. We are confident, therefore, that the PCEs are good approximations of the true model because they explain essentially all of the variance of DMS and $\mathrm{SO}_{2}(97-100 \%)$, and significant amounts of the variance of $\mathrm{H}_{2} \mathrm{SO}_{4}$ and MSA (84-91\%). The slightly poorer fit for the PCE of MSA at 12:00 LT, however, impacts some of the subsequent analysis. This poorer fit is attributed to missing third-order cross terms involving chemical rate constants in the PCE.

\subsubsection{Concentration polynomial chaos expansions}

It is useful to display the polynomial chaos expansions of the concentrations directly because much of the subsequent analysis follows by taking the derivatives and expected values of these PCEs. Table 4 shows truncated forms of the concentration PCEs for DMS, $\mathrm{SO}_{2}, \mathrm{MSA}$, and $\mathrm{H}_{2} \mathrm{SO}_{4}$. The leading terms of the expansions in the table are the concentrations at the mean values of the parameters (i.e. at $\xi=0$ ).

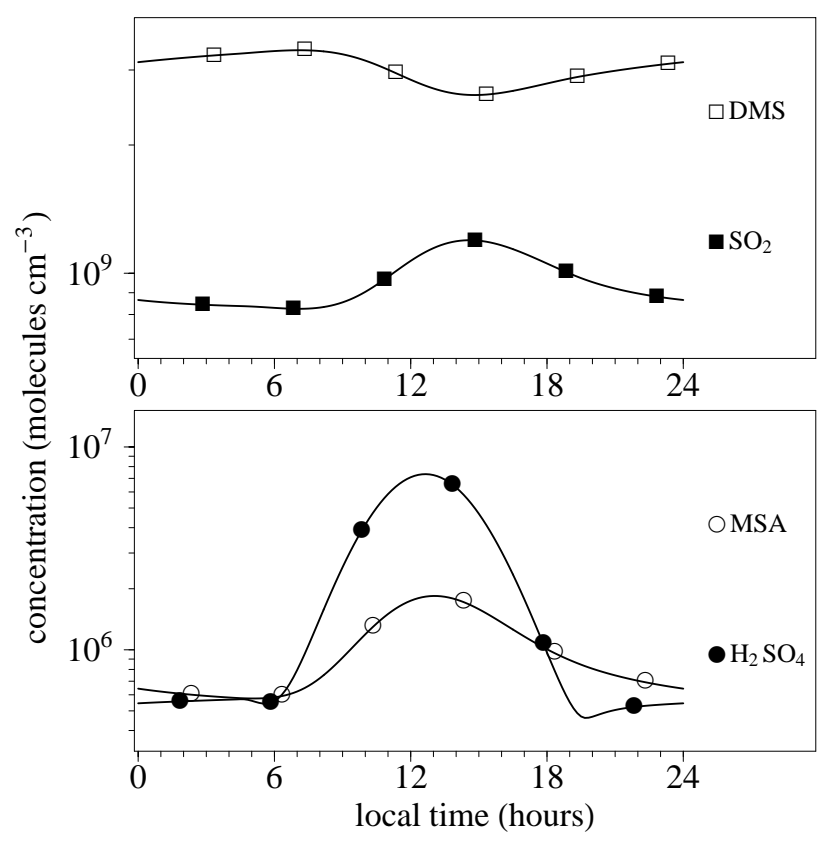

Fig. 3. Diurnal cycles of the concentrations (molecules $\mathrm{cm}^{-3}$ ) of DMS, $\mathrm{SO}_{2}, \mathrm{MSA}$, and $\mathrm{H}_{2} \mathrm{SO}_{4}$ at the mean values of the parameters.

The signs of the PCE coefficients $(+/-)$ indicate whether the concentrations increase $(+)$ or decrease $(-)$ for increases in the magnitude of the specified parameter away from its mean value. The presence of non-linear terms also signals the potential for generating non-symmetric (i.e. skewed) concentration PDFs from the PCEs. Even in their truncated forms, the PCEs in Table 4 indicate that higher-order terms play an important role in determining the concentrations. The concentration of $\mathrm{SO}_{2}$, for instance, depends on non-linear combinations of heterogeneous removal $\left(\xi_{55}\right)$, DMS emissions $\left(\xi_{57}\right)$, and RMBL mixing $\left(\xi_{58}\right)$. These higher-order terms lead to differences in the uncertainties calculated from DIM and PCM.

\subsection{Local sensitivity analysis}

\subsubsection{Diurnal first-order local sensitivity cycles}

Figure 5 shows the diurnal cycles of the first-order local sensitivity coefficients for DMS, $\mathrm{SO}_{2}, \mathrm{MSA}$, and $\mathrm{H}_{2} \mathrm{SO}_{4}$ derived from Eq. (6) and normalized by Eq. (4). We stress that these time-dependent sensitivity cycles are calculated only at the mean values of the parameters and do not contain any parameter uncertainty information. As shown in Sect. 4.2.3, these cycles will change if calculated at other parameter values, and hence are not appropriate for extrapolating concentration uncertainties. Nonetheless, these local sensitivity cycles are useful for determining the influential source and sink processes (i.e. positive and negative sensitivities) as a function of time at the assigned parameter values. 


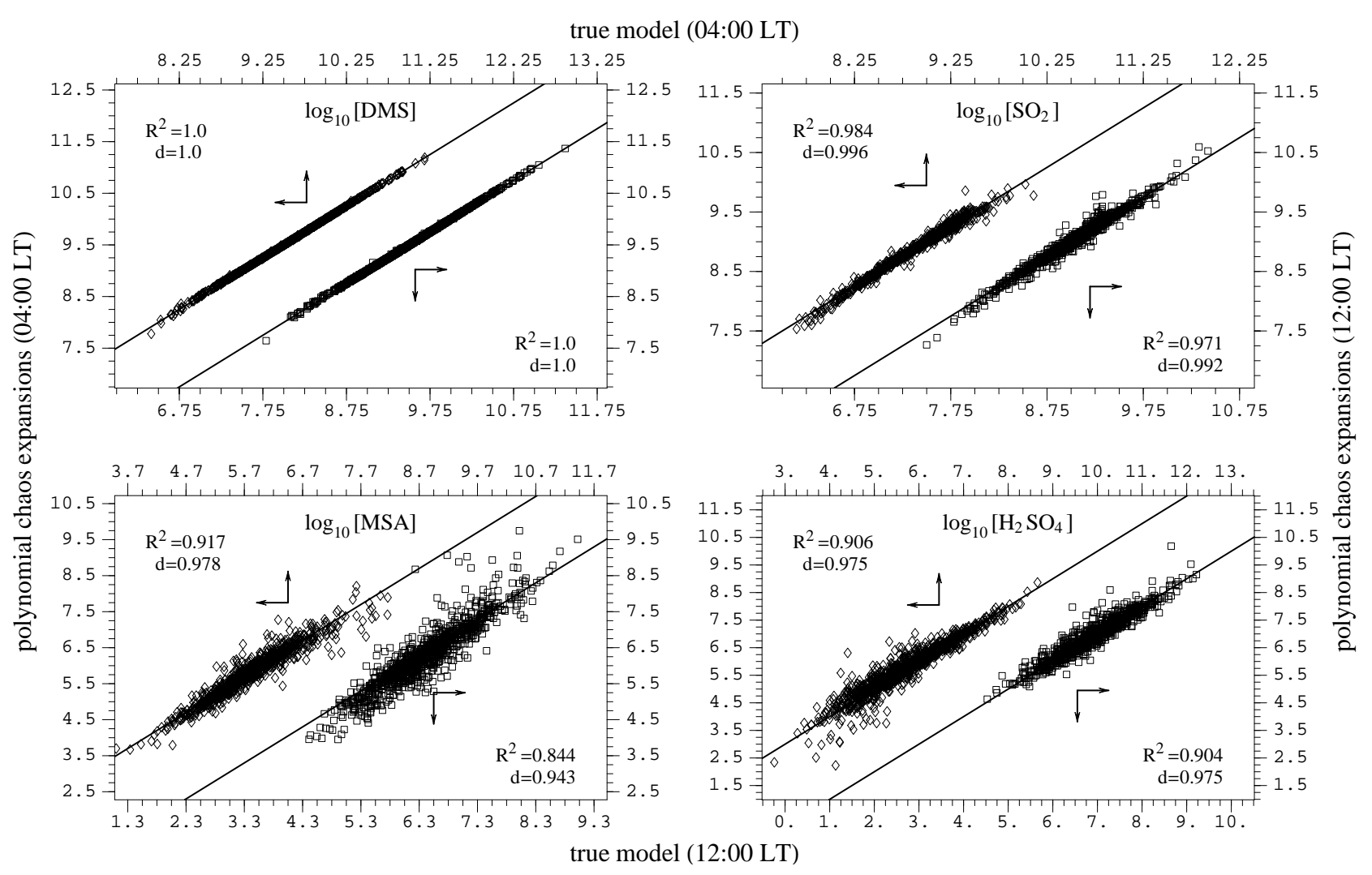

Fig. 4. Correlations of the concentrations ( $\log _{10}$ molecules $\mathrm{cm}^{-3}$ ) from the true model (Eq. 1) and polynomial chaos expansions (Eq. 9). Correlations are displayed at 04:00 LT (diamonds, upper/left axes) and 12:00 LT (squares, lower/right axes) using 103 common sets of parameters sampled randomly from the parameter PDFs. Also shown are the 1:1 lines, coefficients of determination $\left(R^{2}\right)$, and indices of agreement $(d)$.

Table 4. Polynomial chaos expansions of the DMS-related species. The PCEs give the logarithmic concentrations $\left(\log _{10}\right.$ molecules $\left.\mathrm{cm}^{-3}\right)$ in terms of the standard normal random variables $\xi_{k}$, where $k$ denotes the parameter number listed in Table 1. PCEs are ordered by the magnitudes of the coefficients and are truncated after the seventh largest coefficient.

\begin{tabular}{lll}
\hline Time & Species & Polynomial chaos expansion $\left(\log _{10}\right.$ molecules cm $\left.\mathrm{cm}^{-3}\right)$ \\
\hline $04: 00$ & $\mathrm{DMS}$ & $9.51+0.537 \xi_{57}-0.134 \xi_{58}+0.010 \xi_{57}^{2}-0.008 \xi_{3}-0.008 \xi_{58}^{2}-0.006 \xi_{1}+\ldots$ \\
& $\mathrm{SO}_{2}$ & $8.92-0.387 \xi_{55}+0.073 \xi_{55} \xi_{58}+0.062 \xi_{57}-0.061 \xi_{55}^{2}+0.060 \xi_{58}-0.037 \xi_{57} \xi_{58}+\ldots$ \\
& $\mathrm{MSA}^{2}$ & $5.77-0.507 \xi_{54}+0.145 \xi_{57}+0.108 \xi_{58}+0.107 \xi_{6}-0.086 \xi_{57} \xi_{58}+0.083 \xi_{57} \xi_{6}+\ldots$ \\
& $\mathrm{H}_{2} \mathrm{SO}_{4}$ & $5.87-0.539 \xi_{56}-0.413 \xi_{27}+0.405 \xi_{57}+0.287 \xi_{47}+0.287 \xi_{26}-0.134 \xi_{46}+\ldots$ \\
$12: 00$ & $\mathrm{DMS}$ & $9.45+0.537 \xi_{57}-0.138 \xi_{58}-0.021 \xi_{3}-0.015 \xi_{1}+0.010 \xi_{57}^{2}+0.010 \xi_{4}+\ldots$ \\
& $\mathrm{SO}_{2}$ & $9.03-0.293 \xi_{55}+0.168 \xi_{57}-0.086 \xi_{57} \xi_{58}+0.060 \xi_{57}^{2}-0.059 \xi_{55}^{2}+0.034 \xi_{55} \xi_{57}+\ldots$ \\
& $\mathrm{MSA}^{2}$ & $6.14-0.407 \xi_{54}+0.402 \xi_{57}+0.240 \xi_{42}+0.217 \xi_{47}+0.217 \xi_{26}+0.194 \xi_{49}+\ldots$ \\
& $\mathrm{H}_{2} \mathrm{SO}_{4}$ & $6.94-0.516 \xi_{56}+0.297 \xi_{57}-0.197 \xi_{55}-0.189 \xi_{27}+0.136 \xi_{47}+0.135 \xi_{26}+\ldots$ \\
\hline
\end{tabular}

As shown, the majority of the local sensitivity coefficients are extremely time dependent, undergoing rapid changes near midday and some changes in sign. Though complex, these cycles have the following general features related to the four types of model processes: (1) The sensitivities to the chemical production and loss rate constants are positive and negative, respectively, with magnitudes that tend to follow photochemical activity. (2) The sensitivities to the heterogeneous loss parameters are negative and have their smallest magnitudes between morning and noon when photochemistry dominates the concentration changes. (3) The sensitivities to the oceanic DMS source term are positive, but linear 


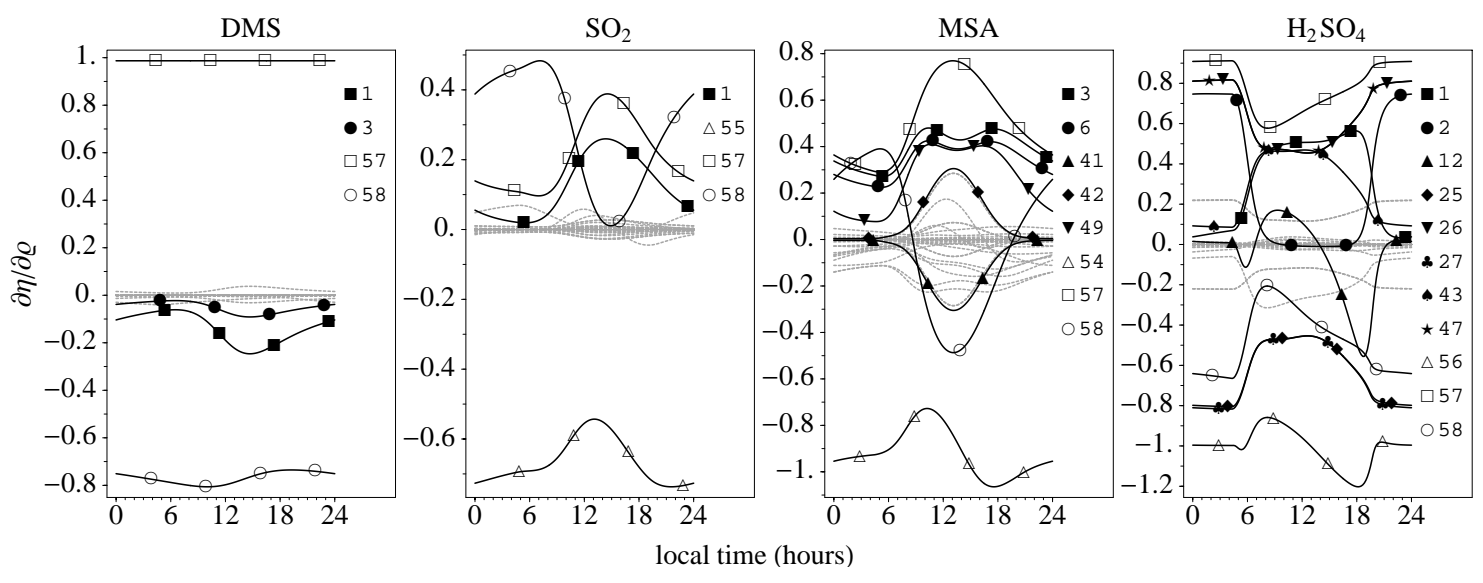

Fig. 5. Diurnal cycles of the first-order local sensitivity coefficients for the DMS-related species calculated using Eq. (6) and normalized using Eq. (4). The "most important" sensitivity coefficients are shown by the dark solid lines with individually labeled symbols and parameter numbers on the right. The most important sensitivities are those with magnitudes within a given threshold of the largest overall value (5\%, $35 \%, 28 \%$, and $35 \%$ for DMS, $\mathrm{SO}_{2}, \mathrm{MSA}$, and $\mathrm{H}_{2} \mathrm{SO}_{4}$, respectively). Filled symbols are used for chemical parameters, and empty symbols are used for heterogeneous removal (empty triangle), DMS emissions (empty square), and RMBL mixing (empty circle). Local sensitivities below the thresholds are shown using gray-dashed lines. Refer to Table 1 for the processes corresponding to the parameter numbers.

for DMS and time varying for the other species. This occurs because a change in DMS emissions yields a proportional change in the DMS concentration, which then undergoes photochemical oxidation. (4) The sensitivities to the vertical mixing coefficient depend on the sign and magnitude of the concentration difference between the free troposphere and boundary layer.

In addition to the general features noted above, specific conclusions from Fig. 5 for the four species are:

(1) DMS is sensitive to very few parameters. These are primarily the parameters for oceanic emissions and vertical mixing, although DMS is also moderately sensitive to the $\mathrm{DMS}+\mathrm{OH}$ abstraction and addition rate constants. The sensitivity to the vertical mixing parameter is always negative because the concentration of DMS decreases with height. From mid-morning to late afternoon, DMS becomes relatively more sensitive to chemistry, due to changes in photochemical activity, and less sensitive to vertical mixing, because of a reduction in the concentration difference between the free troposphere and boundary layer. Interestingly, DMS is not appreciably sensitive to the $\mathrm{NO}_{3}$ oxidation rate constant at night, even though the nighttime $\mathrm{NO}_{3}$ concentration is only 2.2 times lower than the maximum daytime $\mathrm{OH}$ concentration.

(2) $\mathrm{SO}_{2}$ is also sensitive to relatively few parameters. These are the parameters for DMS emissions, vertical mixing, heterogeneous removal, and the DMS+OH abstraction rate constant. The sensitivity to the mixing parameter is always positive because $\mathrm{SO}_{2}$ has a larger concentration in the free troposphere than boundary layer. With time, the sensitivity to mixing decreases from its peak value at 08:00 LT to a near-zero value at about 15:00 LT, which coincides with the lowest and highest $\mathrm{SO}_{2}$ concentrations in Fig. 3. These dynamical mixing changes are caused by temporal variations in the $\mathrm{SO}_{2}$ concentration difference between the free troposphere and boundary layer. This difference is large in the morning, because rapid heterogeneous removal and inefficient chemistry reduce the boundary layer levels, and small in the afternoon, because DMS is chemically oxidized to $\mathrm{SO}_{2}$. Also note that $\mathrm{SO}_{2}$ is always more sensitive to the physical parameters than the rate constants throughout the cycle. Moreover, $\mathrm{SO}_{2}$ is essentially sensitive to only one chemical rate constant, even though many reactions link $\mathrm{SO}_{2}$ to DMS.

(3) MSA is sensitive to many parameters. The largest sensitivities are associated with DMS emissions, vertical mixing, heterogeneous removal, and the rate constants for DMS+OH addition, MSEA formation, the conversion of MSEA to MSA, and reactions producing and destroying $\mathrm{CH}_{3} \mathrm{SO}_{3}$. The sensitivity to the vertical mixing parameter is notable in that it is positive at night and negative during the day. This change in sign indicates that vertical mixing is a source of boundary layer MSA at night and sink during the day, as driven by changes in the concentration in the boundary layer relative to the free troposphere. The sensitivities to the chemical rate constants also show complex behavior with time. During the day, MSA is sensitive to the rate constants for reactions involving MSEA along the $\mathrm{OH}$-addition channel and $\mathrm{CH}_{3} \mathrm{SO}_{3}$ along the $\mathrm{H}$-abstraction channel. At night, MSA retains the sensitivity to the rate constants of some OHaddition reactions, but not any of the $\mathrm{H}$-abstraction reactions. There is also a shift in the relative importance of the OHaddition reactions, which are secondary to DMS emissions during the day, but are among the largest positive sensitivities at night. 

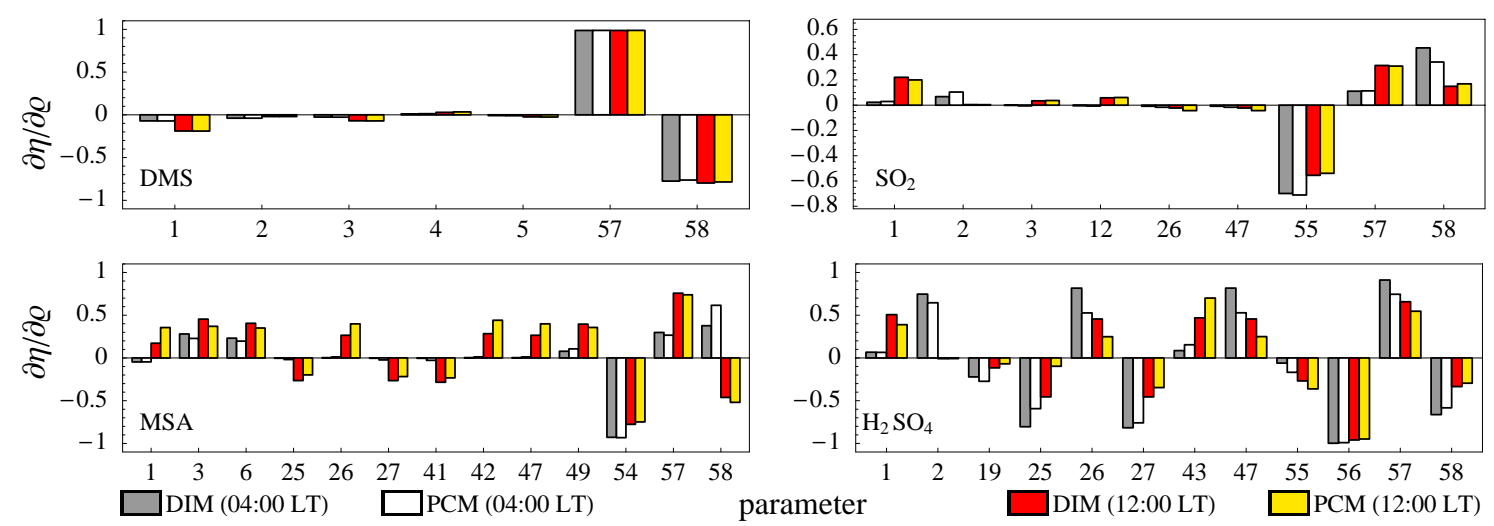

Fig. 6. Comparison of the first-order normalized local sensitivity coefficients using DIM (Eqs. 6 and 4$)$ and PCM ( $\xi=0$ in Eq. 10). The local sensitivities are compared at 04:00 LT (DIM gray, PCM white) and 12:00 LT (DIM red, PCM yellow). Refer to Table 1 for the parameter labels.

(4) $\mathrm{H}_{2} \mathrm{SO}_{4}$ is sensitive to numerous parameters, including those for DMS emissions, heterogeneous removal, and the rate constants of many reactions. $\mathrm{H}_{2} \mathrm{SO}_{4}$ is also negatively sensitive to the vertical mixing coefficient, even though its RMBL and free tropospheric concentrations are equal. As deduced from the signs of the DMS and $\mathrm{SO}_{2}$ sensitivity coefficients to mixing, $\mathrm{H}_{2} \mathrm{SO}_{4}$ is affected mainly by the mixing of DMS, whereby an increase in vertical mixing reduces DMS in the boundary layer and causes a decrease in $\mathrm{H}_{2} \mathrm{SO}_{4}$. This suggests an important, direct link between DMS and $\mathrm{H}_{2} \mathrm{SO}_{4}$ that is independent of $\mathrm{SO}_{2}$. This link is more evident in comparing the sensitivities to the chemical rate constants at day and night. During the day, $\mathrm{H}_{2} \mathrm{SO}_{4}$ is sensitive to the rate constants for $\mathrm{DMS}+\mathrm{OH}$ abstraction, the $\mathrm{SO}_{2}+\mathrm{OH}$ reaction, and reactions that influence $\mathrm{CH}_{3} \mathrm{SO}$ and $\mathrm{CH}_{3} \mathrm{~S}(\mathrm{O}) \mathrm{OO}$. At night, the $\mathrm{OH}$ concentration is low, so the two $\mathrm{OH}$-related sensitivities (i.e. $\mathrm{DMS}+\mathrm{OH}$ abstraction and $\mathrm{SO}_{2}+\mathrm{OH}$ ) are negligible. The oxidation of DMS by $\mathrm{NO}_{3}$, however, is efficient at night, which leads to $\mathrm{CH}_{3} \mathrm{SO}$ in the absence of $\mathrm{OH}$. This then initiates the path $\mathrm{CH}_{3} \mathrm{SO} \rightarrow \mathrm{CH}_{3} \mathrm{~S}(\mathrm{O}) \mathrm{OO} \rightarrow \mathrm{CH}_{3} \mathrm{SO}_{3}$ that is noted in Sect. 2.1.1. The concentration of $\mathrm{H}_{2} \mathrm{SO}_{4}$ is thus highly sensitive to these rate constants at night.

Figure 5 also shows another interesting feature. Highlyparameterized DMS mechanisms, such as the four reaction schemes in Chin et al. (1996) and Gondwe et al. (2003), are commonly used in global models. From the figure, the concentrations of DMS and $\mathrm{SO}_{2}$ are sensitive to just a few rate constants, while MSA and $\mathrm{H}_{2} \mathrm{SO}_{4}$ are sensitive to many. This implies that highly-parameterized DMS mechanisms are sufficient only for oxidizing DMS and forming $\mathrm{SO}_{2}$, not for producing MSA and $\mathrm{H}_{2} \mathrm{SO}_{4}$.

\subsubsection{Comparison of first-order local sensitivities}

Although PCM is a global method, it still provides local sensitivity information at fixed points in the uncertainty spaces of the parameters. Here, we compare the first-order local sensitivities calculated at the mean values of the parameters using DIM (Eq. 6) and PCM ( $\xi=0$ in Eq. 10). The main utility in this comparison is to confirm that, at the mean values of the parameters, PCM identifies the same set of controlling parameters as identified by DIM. This comparison is shown in Fig. 6 for the largest sensitivities.

As shown in the figure, the DIM and PCM local sensitivity coefficients are similar in sign and magnitude. This similarity even holds over time, as exemplified by the sensitivity of MSA to the vertical mixing parameter (parameter 58), which is positive at 04:00 LT and negative at 12:00 LT. The two methods therefore derive the same general set of critical parameters that influence the chemical concentrations.

Though the overall similarity between DIM and PCM is good, there are some differences, particularly for $\mathrm{H}_{2} \mathrm{SO}_{4}$ and MSA. These differences may result partially from the imperfect fits between the true model and polynomial chaos expansions. However, the concentration correlations in Fig. 4 do not show any significant biases towards DIM or PCM. Furthermore, some of the local sensitivity differences in Fig. 6 are larger than the variance differences between the PCEs and true model (i.e. from $R^{2}$ in Fig. 4). This suggests that the differences are also likely due to the local nature of DIM versus the global/higher-order nature of PCM.

\subsubsection{Variations of first-order local sensitivities}

The first-order local sensitivity coefficients from DIM provide a reasonable basis for extrapolating uncertainties (see Eq. 7) only if the sensitivities do not vary greatly in the uncertainty spaces of the parameters. This criterion is tested by evaluating Eq. (10). The equation is a multi-dimensional polynomial in terms of the model parameters, so we vary the parameters one at a time across their $1-\sigma$ uncertainty ranges (i.e. $\left|\xi_{q}\right| \leq 1$ ), while setting all of the other parameters to their mean values (i.e. $\xi_{k}=0$ for all $k \neq q$ ). Figure 7 shows the resulting variations at 12:00 LT. 

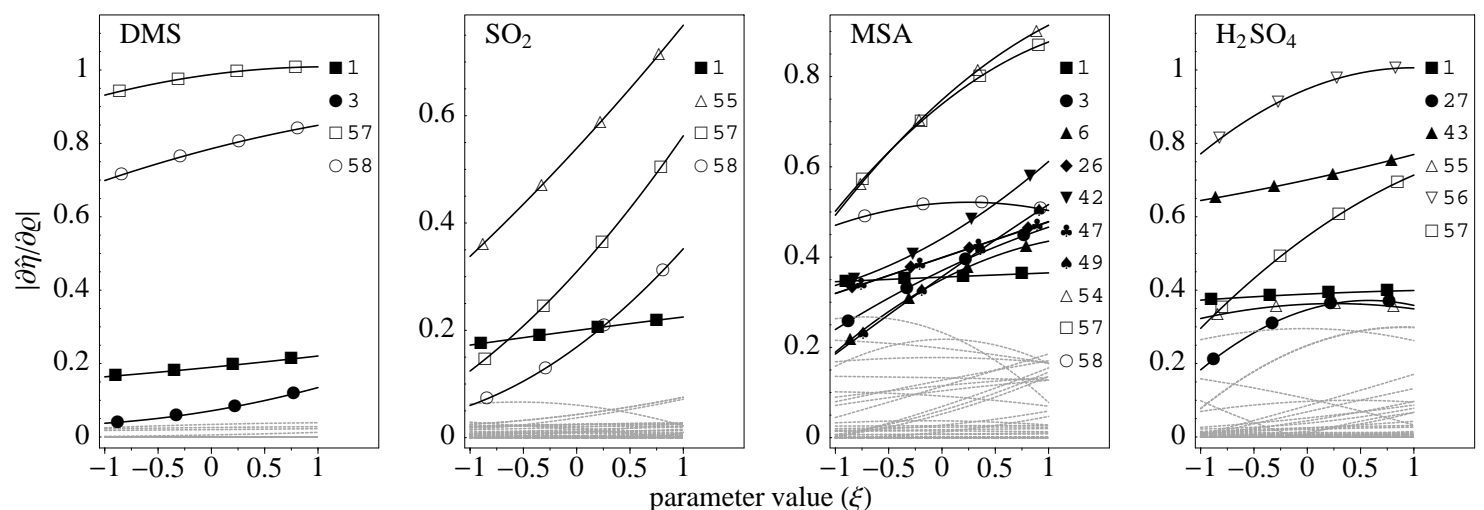

Fig. 7. Magnitudes of the first-order normalized local concentration sensitivities at 12:00 LT as the model parameters are varied across their $1-\sigma$ uncertainty range $(-1 \leq \xi \leq 1)$. Only the labeled parameter is varied $\left(\xi_{q}\right)$ using Eq. (10) with all other parameters set to their mean values $\left(\xi_{k}=0\right)$. The sensitivities are displayed and labeled as described in Fig. 5 (threshold values of 7\%, 20\%, 30\%, and 30\% are used for DMS, $\mathrm{SO}_{2}, \mathrm{MSA}$, and $\mathrm{H}_{2} \mathrm{SO}_{4}$, respectively).
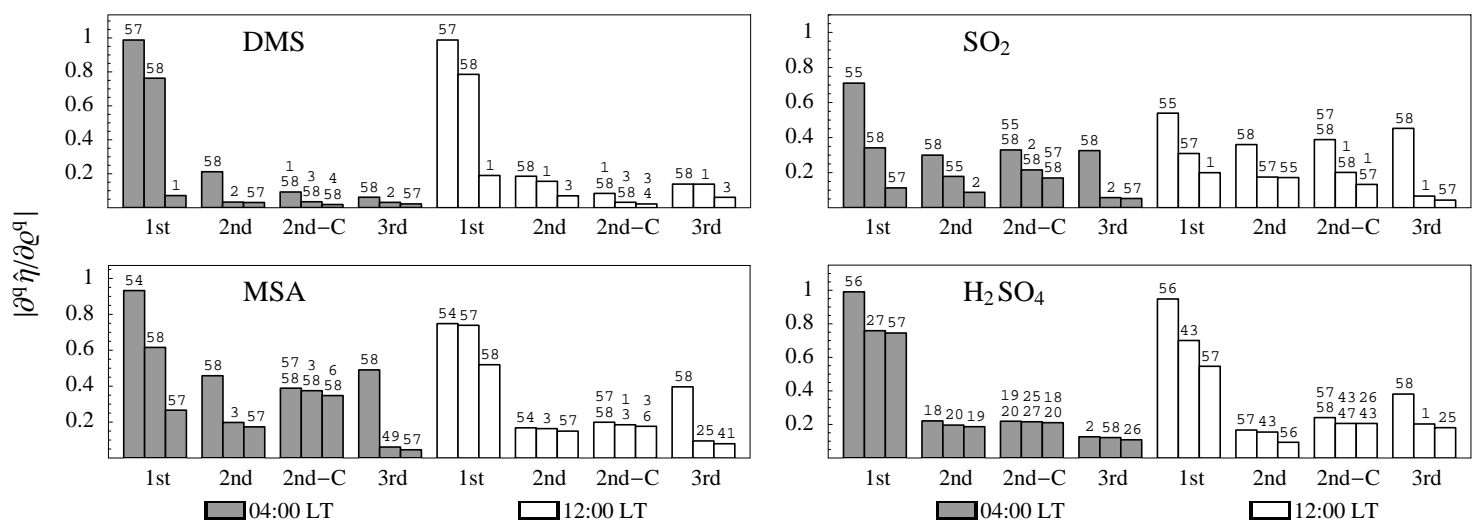

Fig. 8. Magnitudes of the first-, second-, and third-order normalized local sensitivity coefficients using PCM at 04:00 LT (gray) and 12:00 LT (white). Second-order cross sensitivities are denoted by 2nd-C. Only the three largest magnitudes of each order are shown. The parameter numbers are noted at the top of each bar, and $\xi$ is set to zero where applicable. Refer to Table 1 for the parameter labels.

From the slopes of the plots in the figure, the magnitudes of many of the local sensitivity coefficients change dramatically as the paramters are varied. The sensitivity of $\mathrm{SO}_{2}$ to heterogeneous removal, for example, changes by a factor of 2.3 over the 1- $\sigma$ range of parameter 55 . Many of the sensitivities for MSA and $\mathrm{H}_{2} \mathrm{SO}_{4}$ also experience very large variations. Except for maybe DMS, which has small slopes in Fig. 7, we conclude that the local sensitivity coefficients are not appropriate for estimating the concentration uncertainties. The incorrect extrapolation of uncertainties from firstorder local sensitivities has been commented on in detail by Saltelli (1999).

There is another interesting feature in Fig. 7 pertaining to the controlling parameters in the DMS cycle. The majority of the plots in the figure have positive slopes, and the largest slopes are generally related to the physical parameters. Figure 7 therefore shows that the parameters associated with DMS chemistry are relatively more important under condi- tions of low DMS emissions, weak mixing in the RMBL, and low rates of scavenging by aerosols.

\subsubsection{Higher-order local sensitivities}

Higher-order local sensitivity coefficients provide a measure of non-linearities and parameter interactions in the DMS system. Higher-order sensitivities are thus another critical test of the potential for a first-order local analysis using DIM to neglect important and relevant features in sensitivity and uncertainty studies. Figure 8 displays the magnitudes of the three largest first-, second-, and third-order local sensitivity coefficients using Eqs. (10) and (11).

As shown in the figure, the first-order local sensitivities tend to be larger than the higher-order terms because the concentration PCEs are mainly linear in the parameters. There are, however, many extremely large secondand third-order sensitivities, particularly for $\mathrm{SO}_{2}$ and MSA. 

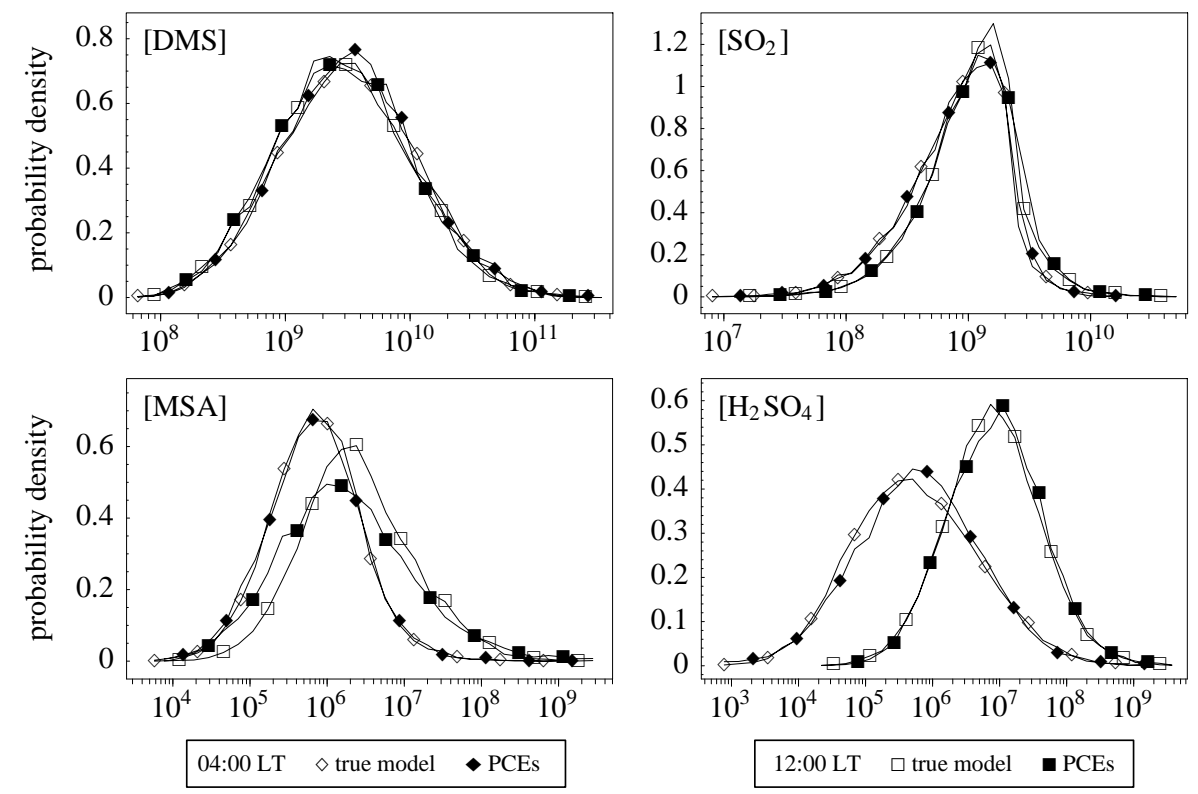

Fig. 9. Probability density functions of the DMS-related concentrations (molecules $\mathrm{cm}^{-3}$ ) using Monte Carlo sampling on the polynomial chaos expansions (PCEs, filled symbols) and true model (empty symbols) at 04:00 LT (diamonds) and 12:00 LT (squares). Sample sizes of $10^{4}$ were used and the PDFs were normalized over 30 equally-spaced bins between the minimum and maximum concentrations.

Upon inspection, the most significant higher-order local sensitivities are related to the RMBL mixing parameter. To illustrate a higher-order effect involving mixing, consider an increase in the mixing parameter. This increase reduces DMS in the RMBL, which reduces the amount of $\mathrm{SO}_{2}$ produced from the oxidation of DMS, but it also increases the influx of $\mathrm{SO}_{2}$ into the RMBL. Figure 8 therefore shows that higherorder processes are important in our DMS model. Because the uncertainty estimates from DIM (i.e. Eq. 7) neglect these higher-order terms, the uncertainty analysis in the next section uses only PCM.

\subsection{Global sensitivity and uncertainty analysis}

\subsubsection{Statistical properties}

Propagating the uncertain parameters through the model leads to the concentration PDFs of DMS, $\mathrm{SO}_{2}, \mathrm{MSA}$, and $\mathrm{H}_{2} \mathrm{SO}_{4}$ shown in Fig. 9. Two sets of PDFs are compared in the figure. One set is from Monte Carlo sampling on the true model (Eq. 1) and the other from sampling the polynomial chaos expansions (Eq. 9). As shown in the figure, the two sets of concentration PDFs have similar characteristics (i.e. shapes and positions). This good comparison therefore supplies additional support (i.e. in addition to the correlations in Sect. 4.1.2) that the PCEs adequately represent the true model and gives us confidence in using PCM for the global analysis. There is a noticeable difference for MSA at 12:00 LT, however, in which the PDF from the true model is slightly narrower and shifted to higher concentrations. The
Table 5. Statistical properties of the DMS-related logarithmic concentrations calculated from the expected values of the polynomial chaos expansions. The values are in units of $\log _{10}$ molecules $\mathrm{cm}^{-3}$.

\begin{tabular}{lllll}
\hline Time & Species & Mean & Variance & Skewness \\
\hline \multirow{2}{04:00}{} & $\mathrm{DMS}$ & 9.51 & 0.30 & 0.11 \\
& $\mathrm{SO}_{2}$ & 8.90 & 0.17 & -0.82 \\
& $\mathrm{MSA}$ & 5.84 & 0.38 & 0.07 \\
& $\mathrm{H}_{2} \mathrm{SO}_{4}$ & 5.78 & 0.87 & -0.02 \\
& & & & \\
$12: 00$ & $\mathrm{DMS}$ & 9.45 & 0.30 & 0.11 \\
& $\mathrm{SO}_{2}$ & 9.03 & 0.16 & -0.47 \\
& $\mathrm{MSA}$ & 6.25 & 0.78 & 0.45 \\
& $\mathrm{H}_{2} \mathrm{SO}_{4}$ & 6.93 & 0.51 & 0.12 \\
\hline
\end{tabular}

slightly poorer fit for MSA at noon is also evident by the relatively lower $R^{2}$ value in Fig. 4.

Qualitatively from Fig. 9, the concentrations of DMS and $\mathrm{SO}_{2}$ are moderately uncertain, while the concentrations of MSA and $\mathrm{H}_{2} \mathrm{SO}_{4}$ are highly uncertain. With time, the most probable values for DMS and $\mathrm{SO}_{2}$ are largely invariant, but for MSA and $\mathrm{H}_{2} \mathrm{SO}_{4}$ they shift from lower to higher concentrations between 04:00 LT and noon. These shifts are related to the amplitudes of the diurnal cycles in Fig. 3 relative to the concentration uncertainties. $\mathrm{SO}_{2}$, for instance, has a larger uncertainty than diurnal amplitude, so the PDFs for $\mathrm{SO}_{2}$ nearly overlap in time. 

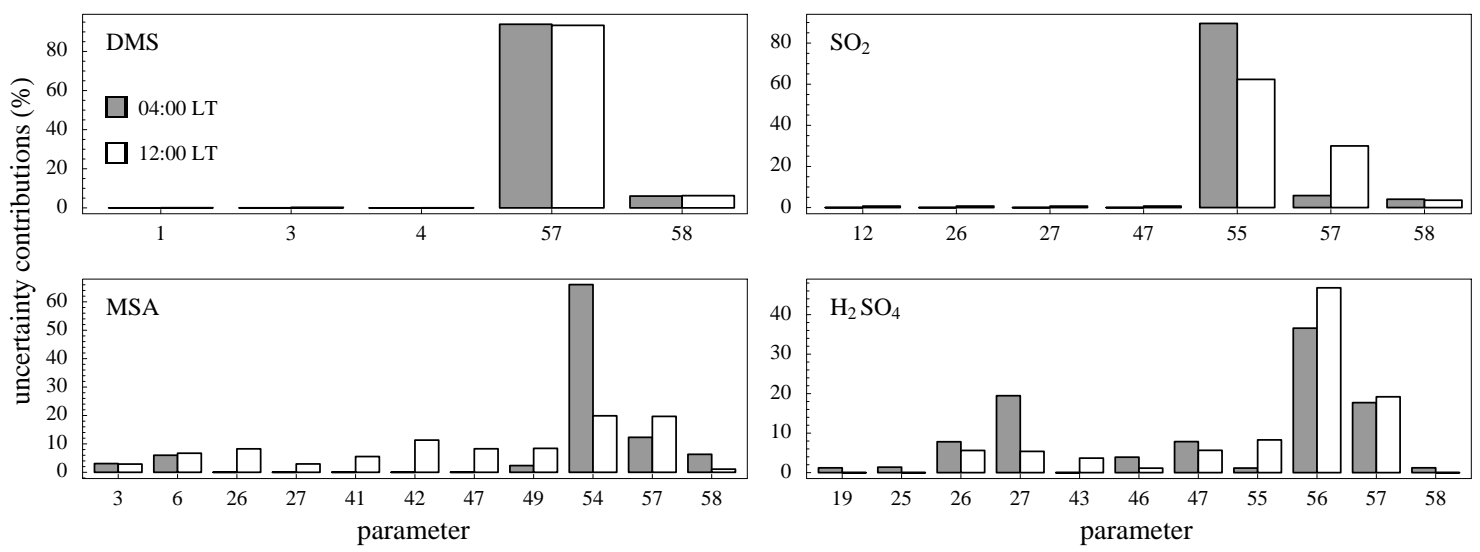

Fig. 10. Parameter-based uncertainty contributions (\%) for the DMS-related species at 04:00 LT (gray) and 12:00 LT (white). Only the contributions greater than $0.01 \%, 0.5 \%, 1 \%$, and $1 \%$ are displayed for DMS, $\mathrm{SO}_{2}, \mathrm{MSA}$, and $\mathrm{H}_{2} \mathrm{SO}_{4}$, respectively. Refer to Table 1 for the parameter labels.

Quantitatively, the mean values of the log-scaled concentrations using Eq. (14) are listed in Table 5. The mean concentrations using PCM are essentially identical to those of true model (not shown in the table) except for MSA at noon (i.e. true model $\approx 6.38$ ). This implies that the $\alpha_{0}$ coefficients of the PCEs are excellent estimators of the mean values. It is also useful to compare the mean values in Table 5 with the leading coefficients in Table 4, where the latter equal the logscaled concentrations at the mean values of the parameters (i.e. $\xi=0$ ). Of the two sets of values, there is good correspondence only for DMS. This indicates a sufficient degree of nonlinearity such that running the model at the mean values of the parameters does not give good estimates for the mean values of the concentrations.

An important part of the global analysis is to quantify the net uncertainties in the sulfur-bearing concentrations. The net uncertainties are associated with the variances, which are calculated by Eq. (15) and listed in Table 5. As with the mean values, the variances of the PCEs are nearly equal to those of the true model (not shown), except for MSA at noon (i.e. true model $\approx 0.52$ ). To quantify the concentration uncertainties, the variances are converted to uncertainty factors $(\phi)$ using $\log _{10} \phi=\sigma_{\hat{\eta}}$. This conversion shows that the concentrations of DMS and $\mathrm{SO}_{2}$ are uncertain by factors of approximately 3.5 and 2.5, respectively, while MSA and $\mathrm{H}_{2} \mathrm{SO}_{4}$ are uncertain by factors ranging between about 4.1 to 8.6. Interestingly, $\mathrm{SO}_{2}$ is less uncertain than DMS, even though $\mathrm{SO}_{2}$ is produced by an extensive set of uncertain chemical reactions. This occurs because $\mathrm{SO}_{2}$ is also less sensitive to the model parameters (e.g. see Fig. 6). Another interesting feature is that the uncertainty of $\mathrm{H}_{2} \mathrm{SO}_{4}$ is larger at night than midday, even though the overall chemical activity is lower. This results from the enhanced sensitivity of $\mathrm{H}_{2} \mathrm{SO}_{4}$ to production through the highly-uncertain non- $\mathrm{SO}_{2}$ pathway at night (e.g. see Fig. 5).
The concentration skewness values using Eq. (17) are also listed in Table 5. These values are listed mainly for qualitative reasons because skewness estimates are less robust than estimates of lower-order statistical moments. The skewness values nonetheless confirm that the $\mathrm{SO}_{2}$ concentration PDFs shown in Fig. 9 have long tails to the left of the mean values. Using PCM, the sources of $\mathrm{SO}_{2}$ asymmetry can be ascertained from the magnitudes of the higher-order terms in the PCEs because, from the central limit theorem, sums and products of independent random variables tend towards normal (symmetric) and lognormal (asymmetric) distributions, respectively. Referring to Table 4 , the PDFs of $\mathrm{SO}_{2}$ are asymmetric primarily because of combinations of the parameters for heterogeneous removal, DMS emissions, and RMBL mixing.

\subsubsection{Uncertainty contributions}

The second major goal of the global analysis is to partition the net concentration uncertainties into contributions from the uncertain parameters. This is done on a per parameter basis using Eq. (16), which includes contributions from pairs of uncertain parameters. The results are displayed in Fig. 10. First note the contrast between Figs. 6 and 10, which highlights the important distinction between the local sensitivity analysis and global uncertainty analysis. Fig. 6 shows that $\mathrm{SO}_{2}$ is locally sensitive to the $\mathrm{DMS}+\mathrm{OH}$ abstraction rate constant, yet Fig. 10 indicates that this parameter makes a negligible contribution to the uncertainty in $\mathrm{SO}_{2}$.

Fig. 10 serves as a useful guide for reducing the uncertainties in the concentrations of DMS, $\mathrm{SO}_{2}, \mathrm{MSA}$, and $\mathrm{H}_{2} \mathrm{SO}_{4}$. It is clear from the figure that better constraints on the parameters associated with DMS emissions (parameter 57) and heterogeneous removal (parameters 50-56) will go a long way towards reducing the overall concentration uncertainties. Other important general conclusions from the figure are as follows: 
Table 6. Percent contributions to the concentration variances from chemical and physical parameters and cross terms.

\begin{tabular}{ccccc}
\hline \multirow{2}{*}{ Time } & Species & \multicolumn{2}{c}{ Parameters } & Cross terms \\
\cline { 3 - 4 } & & Chemical & Physical & \\
\hline \multirow{2}{*}{$04: 00$} & $\mathrm{DMS}$ & 0 & 100 & 0 \\
& $\mathrm{SO}_{2}$ & 1 & 99 & 4 \\
& $\mathrm{MSA}$ & 14 & 86 & 14 \\
& $\mathrm{H}_{2} \mathrm{SO}_{4}$ & 43 & 57 & 5 \\
& & & & \\
\multirow{1}{*}{$12: 00$} & $\mathrm{DMS}^{2}$ & 0 & 100 & 0 \\
& $\mathrm{SO}_{2}$ & 4 & 96 & 8 \\
& $\mathrm{MSA}$ & 59 & 41 & 23 \\
& $\mathrm{H}_{2} \mathrm{SO}_{4}$ & 25 & 75 & 14 \\
\hline
\end{tabular}

- The uncertainty in DMS emissions contributes more than $90 \%$ to the uncertainty in DMS, but only $5-30 \%$ to the other species. Better knowledge of DMS emissions alone, therefore, will only reduce the uncertainties of the oxidized sulfur compounds by moderate levels.

- The uncertainties in DMS and $\mathrm{SO}_{2}$ are caused by just a few physical parameters. MSA and $\mathrm{H}_{2} \mathrm{SO}_{4}$, in contrast, have uncertainty contributions from many chemical and physical parameters. This implies that it should be relatively easier to reduce the uncertainties in DMS and $\mathrm{SO}_{2}$, than in MSA and $\mathrm{H}_{2} \mathrm{SO}_{4}$.

- The uncertain heterogeneous removal parameters are the primary sources of uncertainty in $\mathrm{SO}_{2}$ and $\mathrm{H}_{2} \mathrm{SO}_{4}$ at night and day, and in MSA at night.

- The initial DMS oxidation rate constants involving $\mathrm{OH}$ and $\mathrm{NO}_{3}$ do not contribute significantly to the concentration uncertainties because they are relatively well understood (i.e. have low parameter uncertainties).

- Although chemical parameters are not the dominant sources of uncertainty, the rate constants associated with the formation and loss of $\mathrm{CH}_{3} \mathrm{~S}(\mathrm{O}) \mathrm{OO}$ make sizable contributions to the uncertainties in $\mathrm{H}_{2} \mathrm{SO}_{4}$ at night and MSA during the day.

- For $\mathrm{H}_{2} \mathrm{SO}_{4}$, there are uncertainty contributions from the rate constants for the isomerization of $\mathrm{CH}_{3} \mathrm{SOO}$ at night and $\mathrm{SO}_{2}+\mathrm{OH}$ reaction at noon. For MSA, notable rate constant contributions originate from midday reactions involving MSEA and $\mathrm{CH}_{3} \mathrm{SO}_{3}$.

- The uncertainty contributions change in time for the non-DMS species, with the most dramatic changes occuring for MSA. At night MSA has essentially no uncertainty contributions from chemical parameters, but at noon nearly $50 \%$ of the net uncertainty in MSA is attributed to eight rate constants. Many of these temporal changes are related to the diurnal local sensitivity profiles in Fig. 5.

- In contrast to Saltelli and Hjorth (1995), the uncertainty contributions from the dissociation rate constant of $\mathrm{CH}_{3} \mathrm{SO}_{2}$ are insignificant, even though this pathway directly forms $\mathrm{SO}_{2}$ and $\mathrm{H}_{2} \mathrm{SO}_{4}$. This discrepancy arises because our DMS model contains non-photochemical processes and additional chemical pathways forming $\mathrm{SO}_{2}$ and $\mathrm{H}_{2} \mathrm{SO}_{4}$.

It is difficult to gauge from Fig. 10 the net impact of the uncertain chemistry because the chemical contributions are spread over a large number of parameters. Using Eq. (16), the contributions from the chemical parameters (1-49) and physical parameters (50-58) are summed up separately and displayed in Table 6. As noted in the table, uncertain physical parameters account for practically all of the uncertainty in DMS and $\mathrm{SO}_{2}$. The aggregated chemical parameters, however, comprise up to $43 \%$ and $59 \%$ of the total uncertainty in $\mathrm{H}_{2} \mathrm{SO}_{4}$ and MSA, respectively. This implies that to achieve significant reductions in the net uncertainties of the oxidized DMS products, a better understanding of many reactions in the DMS mechanism is required. Moreover, the total contribution from pairs of uncertain parameters (i.e. the $\beta^{2}$ terms in Eq. 15) are summed up and displayed in Table 6. This analysis indicates that pairs of parameters account for up to $8 \%$ of the total uncertainty in $\mathrm{SO}_{2}$, up to $23 \%$ in MSA, and as much as $14 \%$ in $\mathrm{H}_{2} \mathrm{SO}_{4}$. As a result, efforts to reduce the uncertainties in the DMS-related concentrations should also seek to gain a better understanding of the interactions between the various processes.

\section{Conclusions}

A box model of the diurnal cycle of DMS in the clear-sky remote marine boundary layer is applied to a set of summertime, mid-latitude conditions observed over the Southern Ocean. The rate constants and physical parameters in the model are treated as sources of uncertainty, and the sensitivities and uncertainties of the gas-phase concentrations of DMS, $\mathrm{SO}_{2}$, MSA, and $\mathrm{H}_{2} \mathrm{SO}_{4}$ are analyzed.

A direct integration method is used to calculate the diurnal cycles of the first-order local sensitivity coefficients for infinitesimal perturbations about the mean values of the parameters. From this local analysis, the sulfur-bearing compounds are found to be especially sensitive to the parameters associated with DMS emissions, mixing with the free troposphere, heterogeneous removal, and the $\mathrm{DMS}+\mathrm{OH}$ addition and abstraction reactions. The largest overall local sensitivity coefficients are related to the physical parameters, not the chemical rate constants. The concentrations of MSA and $\mathrm{H}_{2} \mathrm{SO}_{4}$, however, are appreciably sensitive to numerous rate constants beyond the initial reactions in the 
DMS oxidation mechanism. This implies that many of the highly-parameterized DMS mechanisms employed in largescale models are likely missing key features of DMS chemistry. Large temporal variations are also observed for the computed first-order local sensitivity coefficients, particularly for $\mathrm{H}_{2} \mathrm{SO}_{4}$. At night, sulfuric acid is much more sensitive to the rate constants for a sequence of reactions initiated by DMS+NO $\mathrm{N}_{3}$ and leading to $\mathrm{CH}_{3} \mathrm{SO}_{3}$. These reactions deserve future attention because, for sufficient levels of $\mathrm{NO}_{3}$, they enhance the nighttime production of $\mathrm{H}_{2} \mathrm{SO}_{4}$ in the absence of $\mathrm{SO}_{2}$ and $\mathrm{OH}$.

The probabilistic collocation method is used to propagate the uncertain rate constants and physical parameters through the DMS model. PCM is a global sensitivity and uncertainty method that quantifies the net amounts and sources of uncertainty. From this analysis, the concentrations of DMS and $\mathrm{SO}_{2}$ are uncertain $(1-\sigma)$ by factors of roughly 3.5 and 2.5 , respectively. $\mathrm{SO}_{2}$ is less uncertain than DMS because it is also less sensitive to the model parameters. MSA and $\mathrm{H}_{2} \mathrm{SO}_{4}$ have concentration uncertainties that vary with time and range between factors of 4.1 to 8.6. MSA is found to be more uncertain at midday due to additional production paths that are active during the day. $\mathrm{H}_{2} \mathrm{SO}_{4}$, however, is more uncertain at night because of heightened sensitivities to the nighttime production through a non- $\mathrm{SO}_{2}$ pathway.

The global PCM analysis also identifies the parameterbased sources of uncertainty in the DMS-related compounds. Although all of the compounds are locally sensitive to the $\mathrm{DMS}+\mathrm{OH}$ abstraction rate constant, this parameter does not make significant uncertainty contributions because it is relatively well known. We instead find that the uncertainties in the concentrations are caused predominantly by the uncertain parameters for DMS emissions and heterogeneous scavenging. We recommend that field studies of the DMS cycle in the remote marine boundary layer attempt to quantify these processes so as to reduce the overall uncertainties.

For MSA and $\mathrm{H}_{2} \mathrm{SO}_{4}$, however, we also find that many individual uncertain rate constants contribute at a $5 \%$ or higher level. Collectively, the uncertain rate constants account for up to $59 \%$ and $43 \%$ of the total uncertainty in MSA and $\mathrm{H}_{2} \mathrm{SO}_{4}$, respectively. To achieve substantial reductions in the uncertainties of these two species will therefore require better knowledge of many reactions in the DMS oxidation mechanism. Of the many reactions, our uncertainty analysis suggests initially targeting those reactions associated with the formation and loss of $\mathrm{CH}_{3} \mathrm{~S}(\mathrm{O}) \mathrm{OO}$ and $\mathrm{CH}_{3} \mathrm{SO}_{3}$, which may help to reduce the uncertainties in $\mathrm{H}_{2} \mathrm{SO}_{4}$ at night and MSA during the day.

Acknowledgements. We are grateful to A. Saltelli and the four anonymous reviewers for their many helpful comments. This work was supported by NASA grant NAG5-12099 and the federal and industrial sponsors of the MIT Joint Program on the Science and Policy of Global Change.

Edited by: N. Mihalopoulos

\section{References}

Allan, B. J., Carslaw, N., Coe, H., Burgess, R. A., and Plane, J. M. C.: Observations of the Nitrate Radical in the Marine Boundary Layer, J. Atmos. Chem., 33, 129-154, 1999.

Andreae, M. and Crutzen, P.: Atmospheric Aerosols: Biogeochemical Sources and Role in Atmospheric Chemistry, Science, 276, 1052-1058, 1997.

Atkinson, R., Baulch, D. L., Cox, R. A., Hampson, R., Kerr, J. A., Rossi, M. J., and Troe, J.: Evaluated Kinetic and Photochemical Data for Atmospheric Chemistry: Supplement VI, J. Phys. Chem. Ref. Data, 26, 1329-1499, 1997.

Bandy, A. R., Scott, D. L., Blomquist, B. W., Chen, S. M., and Thorton, D. C.: Low Yields of $\mathrm{SO}_{2}$ from Dimethyl Sulfide Oxidation in the Marine Boundary Layer, Geophys. Res. Lett., 19, 1125-1127, 1992.

Bates, T. S., Lamb, B. K., Guenther, A., Dignon, J., and Stoiber, R. E.: Sulfur Emissions to the Atmosphere from Natural Sources, J. Atmos. Chem., 14, 315-337, 1992.

Bates, T. S., Huebert, B., Gras, J., Griffiths, F., and Durkee, P.: The International Global Atmospheric Chemistry (IGAC) Project's First Aerosol Characterization Experiment (ACE 1): Overview, J. Geophys. Res., 103, 16 297-16318, 1998a.

Bates, T. S., Kapustin, V. N., Quinn, P. K., Covert, D. S., Coffman, D. J., Mari, C., Durkee, P. A., De Bruyn, W. J., and Saltzman, E. S.: Processes controlling the distribution of aerosol particles in the lower marine boundary layer during the First Aerosol Characterization Experiment (ACE 1), J. Geophys. Res., 103, 16369 16383, 1998b.

Berresheim, H., Wine, P. H., and Davis, D. D.: Sulfur in the Atmosphere, in: Composition, Chemistry, and Climate of the Atmosphere, edited by: Singh, H. B., pp. 251-307, Van Nostrand Reinhold, New York, 1995.

Calbó, J., Pan, W., Webster, M., Prinn, R., and McRae, G.: Parameterization of Urban Sub-Grid Scale Processes in Global Atmospheric Chemistry Models, J. Geophys. Res., 103, 3437-3452, 1998.

Campolongo, F., Saltelli, A., Jensen, N. R., Wilson, J., and Hjorth, J.: The Role of Multiphase Chemistry in the Oxidation of Dimethylsulphide (DMS), A Latitude Dependent Study, J. Atmos. Chem., 32, 327-356, 1999.

Capaldo, K. P. and Pandis, S. N.: Dimethylsulfide Chemistry in the Remote Marine Atmosphere: Evaluation and Sensitivity Analysis of Available Mechanisms, J. Geophys. Res., 102, $23251-$ $23267,1997$.

Charlson, R., Lovelock, J., Andreae, M., and Warren, S.: Oceanic Phytoplankton, Atmospheric Sulphur, Cloud Albedo, and Climate, Nature, 326, 655-661, 1987.

Chen, G., Davis, D. D., Kasibhatla, P., Bandy, A. R., Thornton, D. C., Huebert, B. J., Clarke, A. D., and Blomquist, B. W.: A Study of DMS Oxidation in the Tropics: Comparison of Christmas Island Field Observations of DMS, $\mathrm{SO}_{2}$, and DMSO with Model Simulations, J. Atmos. Chem., 37, 137-160, 2000.

Chin, M., Jacob, D. J., Gardner, G. M., Foreman-Fowler, M. S., Spiro, P. A., and Savoie, D. L.: A Global Three-Dimensional Model of Tropospheric Sulfate, J. Geophys. Res., 101, 18667$18690,1996$.

Davis, D., Chen, G., Bandy, A., Thornton, D., Eisele, F., Mauldin, L., Tanner, D., Lenschow, D., Fuelberg, H., Huebert, B., Heath, J., Clarke, A., and Blake, D.: Dimethyl Sulfide Oxidation in the 
Equatorial Pacific: Comparison of Model Simulations with Field Observations for DMS, $\mathrm{SO}_{2}, \mathrm{H}_{2} \mathrm{SO}_{4}(\mathrm{~g}), \mathrm{MSA}(\mathrm{g})$, MS, and NSS, J. Geophys. Res., 104, 5765-5784, 1999.

DeMore, W., Sander, S., Golden, D., Hampson, R., Howard, C., Ravishankara, A., Kolb, C., and Molina, M.: Chemical Kinetics and Photochemical Data for Use in Stratospheric Modeling, Tech. Rep. Evaluation No. 12, Jet Propulsion Laboratory, NASA, Pasadena, CA, 1997.

Dickinson, R. P. and Gelinas, R. J.: Sensitivity Analysis of Ordinary Differential Equation Systems - A Direct Method, J. Comp. Phys., 21, 123-143, 1976.

Gondwe, M., Krol, M., Gieskes, W., Klaassen, W., and de Baar, H.: The Contribution of Ocean-Leaving DMS to the Global Atmospheric Burdens of DMS, MSA, $\mathrm{SO}_{2}$, and $\mathrm{NSS} \mathrm{SO}_{4}^{=}$, Global Biogeochem. Cycles, 17, 1056, doi:10.1029/2002GB001937, 2003.

Hatakeyama, S. and Akimoto, H.: Reactions of $\mathrm{OH}$ radicals with methanethiol, dimethyl sulfide, and dimethyl disulfide in air, J. Phys. Chem., 87, 2387-2395, 1983.

Keller, M., Bellows, W., and Guillard, R.: Dimethylsulfide Production in Marine Phytoplankton, in: Biogenic Sulfur in the Environment, edited by: Saltzman, E. and Cooper, W., pp. 167-182, American Chemical Society, Washington, D.C., 1989.

Koga, S. and Tanaka, H.: Numerical study of the oxidation process of dimethylsulfide in the marine atmosphere, J. Atmos. Chem., 17, 201-228, 1993.

Kukui, A., Bossoutrot, V., Laverdet, G., and Le Bras, G.: Mechanism of the Reaction of $\mathrm{CH}_{3} \mathrm{SO}$ With $\mathrm{NO}_{2}$ in Relation to Atmospheric Oxidation of Dimethyl Sulfide: Experimental and Theoretical Study, J. Phys. Chem. A, 104, 935-946, 2000.

Kukui, A., Borissenko, D., Laverdet, G., and Le Bras, G.: GasPhase Reactions of OH Radicals with Dimethyl Sulfoxide and Methane Sulfinic Acid Using Turbulent Flow Reactor and Chemical Ionization Mass Spectrometry, J. Phys. Chem. A, 107, 57325742, 2003.

Kulmala, M., Laaksonen, A., and Pirjola, L.: Parameterizations for Sulfuric Acid/Water Nucleation Rates, J. Geophys. Res., 103, 8301-8307, 1998.

Leis, J. R. and Kramer, M. A.: The Simultaneous Solution and Sensitivity Analysis of Systems Described by Ordinary Differential Equations, ACM Trans. Math. Software, 14, 45-60, 1988a.

Leis, J. R. and Kramer, M. A.: Algorithm 658: ODESSA - An Ordinary Differential Equation Solver With Explicit Simultaneous Sensitivity Analysis, ACM Trans. Math. Software, 14, 61-67, 1988 b.

Lin, X. and Chameides, W. L.: CCN Formation From DMS Oxidation Without $\mathrm{SO}_{2}$ Acting as an Intermediate, Geophys. Res. Lett., 20, 579-582, 1993.

Liss, P. S. and Merlivat, L.: Air-sea gas exchange rates: Introduction and synthesis, in: The Role of Air-Sea Exchange in Geochemical Cycling, edited by: Buat-Ménard, P. and Reidel, D., pp. 113-127, Norwell, Mass, 1986.

Lucas, D. D.: Mechanistic, Sensitivity, and Uncertainty Studies of the Atmospheric Oxidation of Dimethylsulfide, Ph.D. thesis, Massachusetts Institute of Technology, Cambridge, MA, Center for Global Change Science Report 71, http://web.mit.edu/cgcs/ www/MIT_CGCS_Rpt71.html, 2003.

Lucas, D. D. and Prinn, R. G.: Mechanistic Studies of Dimethylsulfide Oxidation Products Using an Observation- ally Constrained Model, J. Geophys. Res., 107, 4201, doi:10.1029/2001JD000843, 2002.

Lucas, D. D. and Prinn, R. G.: Tropospheric distributions of sulfuric acid-water vapor aerosol nucleation rates from dimethylsulfide oxidation, Geophys. Res. Lett., 30, 2136, doi:10.1029/2003GL018370, 2003.

Mari, C., Suhre, K., Rosset, R., Bates, T. S., Huebert, B. J., Bandy, A. R., Thorton, D. C., and Businger, S.: One-Dimensional Modeling of Sulfur Species During the First Aerosol Characterization Experiment (ACE 1) Lagrangian B, J. Geophys. Res., 104, 21 733-21 749, 1999.

Mayer, M., Wang, C., Webster, M., and Prinn, R. G.: Linking Local Air Pollution to Global Chemistry and Climate, J. Geophys. Res., 105, 22 869-22 896, 2000.

Pan, W., Tatang, M., McRae, G., and Prinn, R.: Uncertainty Analysis of Direct Radiative Forcing by Anthropogenic Sulfate Aerosols, J. Geophys. Res., 102, 21 915-21 924, 1997.

Pan, W., Tatang, M., McRae, G., and Prinn, R.: Uncertainty Analysis of Indirect Radiative Forcing by Anthropogenic Sulfate Aerosols, J. Geophys. Res., 103, 3815-3824, 1998.

Restelli, G. and Angeletti, G. (Eds.): Dimethylsulphide: Oceans, Atmosphere, and Climate, Kluwer, Dordrecht, Netherlands, 1993.

Saltelli, A.: Sensitivity Analysis: Could Better Methods Be Used?, J. Geophys. Res., 104, 3789-3793, 1999.

Saltelli, A., Chan, K., and Scott, E. M. (Eds.): Sensitivity Analysis, John Wiley and Sons, New York, 2000.

Saltelli, A. and Hjorth, J.: Uncertainty and Sensitivity Analyses of OH-Initiated Dimethyl Sulphide (DMS) Oxidation Kinetics, J. Atmos. Chem., 21, 187-221, 1995.

Shaw, G.: Bio-Controlled Thermostasis Involving the Sulfur Cycle, Climatic Change, 5, 297-303, 1983.

Shon, Z., Davis, D., Chen, G., Grodzinsky, G., Bandy, A., Thorton, D., Sandholm, S., Bradshaw, J., Stickel, R., Chameides, W., Kok, G., Russell, L., Mauldin, L., Tanner, D., and Eisele, F.: Evaluation of the DMS Flux and its Conversion to $\mathrm{SO}_{2}$ over the Southern Ocean, Atmos. Environ., 35, 159-172, 2001.

Tatang, M.: Direct Incorporation of Uncertainty in Chemical and Environmental Engineering Systems, Ph.D. thesis, MIT, Cambridge, MA, 1995.

Tatang, M., Pan, W., Prinn, R., and McRae, G.: An Efficient Method for Parametric Uncertainty Analysis of Numerical Geophysical Models, J. Geophys. Res., 102, 21 925-21 932, 1997.

Turnipseed, A. A. and Ravishankara, A. R.: The Atmospheric Oxidation of Dimethyl Sulfide: Elementary Steps in a Complex Mechanism, in: Dimethylsulphide: Oceans, Atmospheres, and Climate, edited by: Restelli, G. and Angeletti, G., pp. 185-195, Kluwer, Dordrecht, 1993.

Urbanski, S. P. and Wine, P. H.: Chemistry of Gas Phase Organic Sulfur-Centered Radicals, in: S-Centered Radicals, edited by: Alfassi, Z. B., pp. 97-140, Wiley, Chichester, 1999.

Verheggen, B. and Mozurkewich, M.: Determination of Nucleation and Growth Rates from Observations of a $\mathrm{SO}_{2}$ Induced Atmospheric Nucleation Event, J. Geophys. Res., 107, 4123, doi:10.1029/2001JD000683, 2002.

von Glasow, R., Sander, R., Bott, A., and Crutzen, P. J.: Modeling Halogen Chemistry in the Marine Boudary Layer 2. Interactions With Sulfur and the Cloud-Covered MBL, J. Geophys. Res., 107, 4323, doi:10.1029/2001JD000943, 2002. 
von Glasow, R. and Crutzen, P. J.: Model Study of Multiphase DMS Oxidation With a Focus on Halogens, Atmos. Chem. Phys., 4, 589-608, 2004,

SRef-ID: 1680-7324/acp/2004-4-589.

Wanninkhof, R.: Relationship Between Wind Speed and Gas Exchange over the Ocean, J. Geophys. Res., 97, 7373-7382, 1992.
Xiu, D. and Karniadakis, G. E.: Modeling uncertainty in flow simulations via generalized polynomial chaos, J. Comput. Phys., 187, 137-167, doi:10.1016/S0021-9991(03)00092-5, 2003.

Yin, F., Grosjean, D., and Seinfeld, J.: Photooxidation of Dimethyl Sulfide and Dimethyl Disulfide. I. Mechanism Development, J. Atmos. Chem., 11, 309-364, 1990. 